\title{
Juguetes fonográficos: prejuicio y representación en la era pre-cinema (1900-1925)
}

institucional.us.es/ambitos/

\section{Jorge L. Crespo Armáiz}

Sistema Universitario Ana G. Méndez

ac_jcrespo@suagm.edu

English Version: Phonographic toys: prejudice and representation in the "pre-cinema" age (1900-1925)

\begin{abstract}
Resumen
El origen del concepto experiencial de la denominada "sociedad mediática" se remonta mucho más allá de la explosión de las tecnologías de la informática y las telecomunicaciones hacia finales de siglo XX. Durante las primeras décadas del pasado siglo, se desarrolló un proceso de integración de nuevas tecnologías, el cual sentó las bases para el surgimiento del cinema, más que como innovación, como referente indispensable de la moderna sociedad del espectáculo. La conjunción técnica del sonido grabado con la fotografía en movimiento fue fundamental en este proceso. Previo a esta integración se desarrolló un breve período pre-cinema, en el

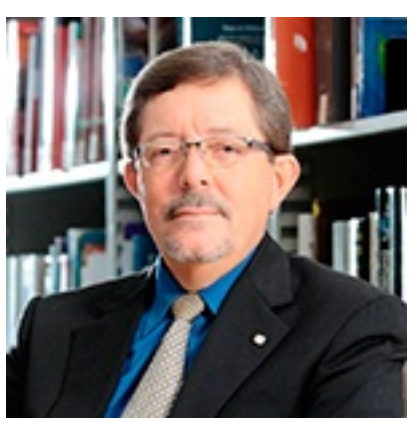

cual surgieron innovaciones de entretenimiento familiar y público, las cuales

tomaron forma en una serie de juguetes mecánicos accionados por el mecanismo giratorio del fonógrafo, de reciente invención. Al igual que cualquier juguete convencional o genérico, los llamados "juguetes fonográficos" deben estudiarse como artefactos culturales, esto es, como parte de la cultura material de un grupo social. Más

allá del rol del juguete como instrumento genérico de socialización, un gran número de juguetes fonográficos reflejan con claridad una fuerte carga valorativa y una intencionalidad de connotación de elementos de prejuicio y alteridad respecto a raza, género y etnicidad. A través de éste trabajo se analizan varios ejemplos de juguetes fonográficos manufacturados y distribuidos por varias compañías principales entre 1915 y 1920, y se evalúa la

forma en que imagen, movimiento, sonido y texto escrito se conjugan en éstos para trasmitir una serie de elementos discursivos y narrativas de alteridad referentes a estos diversos grupos.
\end{abstract}

\section{Palabras clave}

Juguetes fonográficos, cinema, sociedad mediática, representación, prejuicio.

The origin of the experiential concept known today as the "media society" goes back beyond the so-called explosion of the information and telecommunication technologies at the end of the twentieth century. During the first decades of the last century, a process of integration of new emerging technologies was developed, providing the conditions for the creation of cinema - more than an innovation, as an indispensable reference of the birth of

the modern "spectacle society". The technical integration of recorded sound with moving photography was essential in this process. But short before this crucial integration, a brief "pre-cinema" period emerged, in which several domestic and public entertainment innovations were developed, in the form of a series of mechanical toys activated by the spinning mechanism of the phonograph or gramophone, of recent invention. As any other conventional or generic toy, the so-called "phonotoys" should be considered and studied as cultural artifacts, that

is, as part of the material culture of any given social group. Much more than the expected role of toys as conventional means of socialization, a large number of phonotoys reflect a strong values agenda, and a clear intentionality of connotation of prejudice and alter representation of race, genre and ethnicity. In this work we analyze several examples of phonographic toys manufactured and distributed by various companies between 1915 and 1920, identifying the different ways in which visual image, movement, sound and even written texts combine to transmit a series of narratives and discourses regarding these diverse groups. 
Phonographic toys, cinema, mediatic society, prejudice, representation.

\section{INTRODUCCIÓN}

Los términos "sociedad mediática" o sociedad del "espectáculo" han cobrado una particular y fuerte connotación en la época que vivimos durante éstas primeras décadas del siglo XXI. La conjunción de varios factores de naturaleza global ha abonado a estas caracterizaciones. El avasallador avance tecnológico - particularmente en los campos de la informática y las telecomunicaciones - ha provisto la infraestructura necesaria para potenciar el ya tan común fenómeno de las comunicaciones instantáneas y el flujo de información sin barreras a través del mundo, sea ésta información numérica, textual o visual. Lo que inició como un proceso de modernización tecnológica limitado al mundo empresarial durante las décadas de los '70 y '80 del pasado siglo, y que luego evolucionó hacia una masificación de los procesos de comunicación electrónica por medio de la red de internet durante la década de los '90, se ha transfigurado a inicios del nuevo milenio en un fenómeno orgánico a través de las llamadas "redes sociales", las cuales han representado un proceso de empoderamiento y libertad de expresión que incluso ha venido a retar los cimientos de muchas sociedades tradicionalistas.

En segundo lugar, la innegable hegemonía del capitalismo (o neoliberalismo, en sus distintas vertientes), tras la debacle del modelo de centralización socialista en la última década del siglo XX, ha reafirmado la prevalencia del esquema corporativo transnacional, fuertemente dependiente de los consabidos modelos de distribución, promoción y mercadeo, y los cuales, a su vez, han encontrado en los modernos canales mediáticos y tecnológicos su más eficiente aliado. Periódicos y revistas (en su mayoría digitalizados a través de páginas cibernéticas); el cine, radio y televisión (también digitalizados y satelitales); la red de internet con su infinito menú de temas e intereses, buscadores, páginas y "blogs"; así como las redes de interacción social - todo ello concentrado y sintetizado en un accesorio electrónico personal, sea en la forma de un teléfono "inteligente", una "tableta" electrónica, o un reloj pulsera multi-medios - hacen de cada individuo un "punto de venta" único, seriado, clasificado, analizado, y - por qué no decirlo - controlado. No hace falta estar parado en medio de Time Square para recibir, en cualquier parte del mundo y con la misma o mayor intensidad, nuestra dosis predeterminada de "información", el sentido de urgencia consumerista ante el nuevo y más llamativo producto, o la visión de mundo sanitizada y homogenizada que más conviene a los círculos de poder prevalecientes.

No obstante, la génesis histórica de la actual sociedad "mediática" tiene sus raíces en desarrollos tecnológicos mucho más lejanos y anteriores a la llamada era de la informática de finales de siglo XX. Dichos antecedentes tecnológicos, paulatinamente, fueron modificando, no solo la experiencia sino más aún las mentalidades de las sociedades modernas con respecto a los procesos de generación, distribución y consumo de información en sus distintas vertientes, sean éstas textuales, visuales e incluso auditivas.

\section{FOTOGRAFÍA, FONOGRAFÍA Y CINEMATOGRAFÍA}

El desarrollo de la invención fotográfica (ca. 1839) constituyó sin dudas uno de los mayores puntos de inflexión en la evolución de los procesos de reproducción [i] y difusión de información, en este caso visual. De la misma forma en que la invención de la imprenta de tipos movibles a mediados del siglo XV representó una nueva era en la difusión del conocimiento a través del texto escrito, la fotografía estableció un nuevo paradigma en la reproducción y difusión de la información visual, una "democratización" del texto iconográfico, reservado hasta ese momento a un reducido número de privilegiados y limitado a la reproducción artística de paisajes y retratos de la nobleza, el clero y la nueva burguesía. [ii] No abundaremos aquí en el intenso debate - aún vigente entre los correspondientes defensores o detractores de la fotografía y la pintura, ni mucho menos en las diversas formas en que el medio fotográfico ha venido a impactar las mentalidades y nociones modernas referentes a la objetividad, documentación, registro, interpretación e impacto cultural de las imágenes visuales. Para ello remitimos al lector a la extensa bibliografía existente sobre este tema, y de la cual proveemos algunas referencias más adelante. Baste dejar establecida la aportación crítica y medular de la fotografía en el desarrollo de esa nueva visión de mundo, este nuevo paradigma en el cual la percepción visual se constituirá en uno de los constructos indispensables del ser humano en la recepción e interpretación de su entorno físico y 
social.

De forma muy similar a la invención fotográfica de mediados de siglo, hacia fines del período decimonónico otra invención vino a representar un nuevo punto de inflexión en la manera de reproducir, diseminar y percibir información: la grabación y reproducción del sonido. Tomando como base los desarrollos de Alexander Graham Bell en el nuevo campo de la trasmisión de sonidos a distancia (telefonía, ca. 1876), así como su propia experiencia en la industria de telegrafía, hacia 1877 Thomas A. Edison desarrolló un primer artefacto capaz de grabar y reproducir la voz humana. [iii] Aunque en su origen Edison no adscribió mucha importancia a su "fonógrafo", al percatarse de la rápida aparición de imitadores y empresas interesadas, de inmediato se dio a la tarea de perfeccionar el mismo, dando inicio a toda una nueva industria cuyas repercusiones económicas y culturales continúan impactando la sociedad moderna.
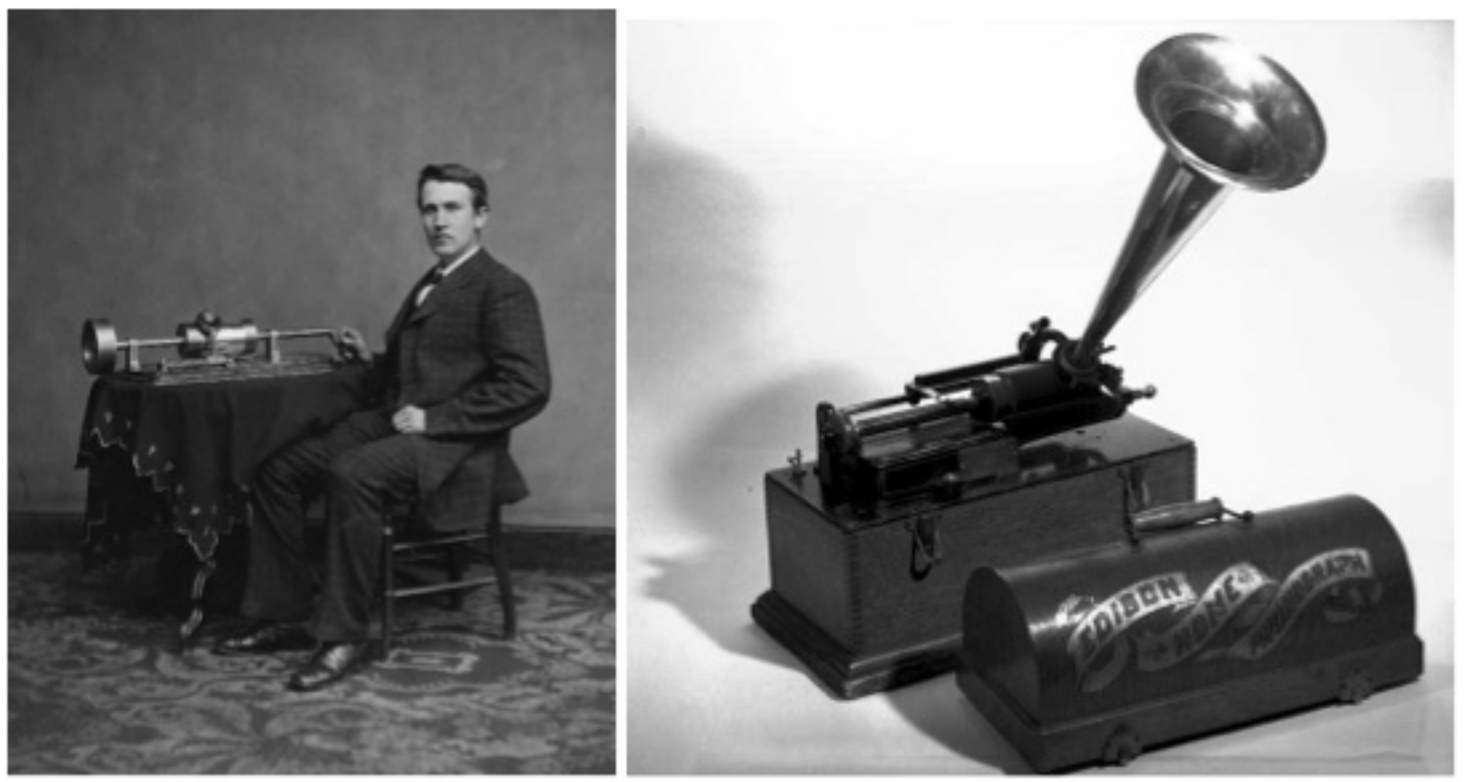

\section{IZQUIERDA: Thomas Edison junto a su segundo prototipo de fonógrafo (fotografiado por} Mathew Brady, 1878). DERECHA: Modelo comercial del "Edison Home Phonograph"

La primera grabación de un sonido inteligible en el fonógrafo de cilindros de Edison fue la canción infantil "Mary had a little lamb" (1877). El impacto cultural y social de la nueva invención fue inmediato. Aunque en principio se intentó vender el nuevo aparato para aplicaciones puramente comerciales (especialmente para uso de taquígrafos), muy pronto se hizo claro el mayor potencial económico de la invención en el campo del entretenimiento. La compañía Pacific Phonograph Co. estableció varios fonógrafos operados por tragamonedas en algunas ferias y establecimientos comerciales, probando ser un éxito rotundo con el público. Aunque solo podían reproducir una sola canción por moneda, estas primeras máquinas públicas dieron impulso a la creación de la industria de grabaciones musicales. Por un tiempo los "cilindros" más vendidos se limitaban a sermones, discursos políticos y otros tipos de grabaciones de la voz humana, no obstante, ya entrado el nuevo siglo las grabaciones de marchas (John Philip Sousa), bailes (ragtime, fox-trot, two-step) y distintos géneros de música popular tomaron el lugar de preferencia en la demanda de una nueva clase media que emergía al cierre del siglo como secuela de la revolución industrial, la expansión territorial y la nueva posición hegemónica de los Estados Unidos en el hemisferio. [iv]

Hacia 1900 Emile Berliner desarrolló el formato de grabación sobre discos planos de plástico (que prevalecerá con distintas innovaciones hasta finales de siglo XX), los cuales desplazaron los antiguos cilindros de Edison, dando paso al crecimiento y diversificación de la industria de grabación musical. En 1901 Berliner estableció la Victor Talking Machine Co., la cual se constituyó rápidamente en líder del mercado, siendo más tarde adquirida por la Radio Corporation of America (RCA), denominándose como la RCA-Victor. Entre 1900 y 1920 se habían establecido en los Estados Unidos alrededor de 240 compañías fabricantes de fonógrafos, muchas de las cuales también producian y mercadeaban discos fonográficos. Entre ellas sobresalen la Columbia, Victor (RCAVictor), Brunswick, y Pathé. [v] El crecimiento, diversificación y competencia dentro de la industria llevó al desarrollo de modelos de fonógrafos más baratos y de mejor calidad, convirtiéndose rápidamente en uno de los 
productos o mercancías básicas ("commodity") dentro de todo hogar típico de clase media. Tal y como ocurrió con el texto escrito tras la invención de la imprenta, o con las imágenes visuales con la fotografía, debido a que ahora la música estaba disponible prácticamente en cualquier lugar y en cualquier momento, se desarrolló un fenómeno o experiencia social novel, en el sentido de que grandes masas poblacionales comenzaron a estar expuestos a una mayor amplitud de tipos de música, no solo local sino de otros países.

Al igual que la imprenta, el telégrafo, el teléfono y la fotografía; el fonógrafo representó un proceso de acortar distancias, de ampliar accesos, de "democratización", de reproducción y difusión de conocimiento - una nueva percepción del mundo, no ya a través del texto o la imagen, sino del sonido. Claro está, al igual que en el caso de todas esas invenciones que le antecedieron, dicha percepción de mundo a través del medio auditivo estará mediatizada culturalmente, en función de las diversas instancias en que el artefacto y proceso mecánico sean intervenidos por un agente cultural, sea éste el autor de una letra, el compositor de una melodía, el artista o artistas que la interpretan, el productor o ente comercial que la distribuye.

Hacia la segunda década del siglo XX, la conjunción de la tecnología de grabación sonora y la tecnología de la imagen fotográfica en movimiento dieron origen a otra industria de gran impacto cultural: la industria cinematográfica. Aunque generalmente se adscribe el desarrollo del cinematógrafo a los trabajos de los hermanos Lumiere en Francia, como tantas otras innovaciones tecnológicas (como ya hemos visto respecto a la fotografía o el fonógrafo), este avance vino a ser resultado de siglos de experimentación, particularmente en los campos de la fisiología ocular, la visión y los estudios ópticos. [vi] Desde la antigua noción de la "cámara oscura" (cuyos principios eran ya conocidos desde el siglo IV a.c., tanto por filósofos chinos como griegos) y la proyección de imágenes a través de la "lámpara mágica" de positivos en cristal ("magic lantern"), pasando por la estereoscopía (Charles Wheatstone; David Brewster, ca. 1850), el desarrollo mismo de la fotografía (Niépce; Daguerre; Talbot, ca. 1850), la cronofotografía (que llevó a la fotografía en movimiento), y la infinidad de aparatos y juguetes ópticos tales como el caleidoscopio, el taumatropo, el zoótropo, el praxinoscopio, y el kinetoscopio de Edison - son innumerables las instancias y campos que aportaron al desarrollo de la experiencia de ilusión que representa el cinema dentro del entramado mediático-cultural contemporáneo. La adición de la "banda sonora", es decir, la inserción del sonido sincronizado con la imagen visual en la cinta cinematográfica fue la innovación climática que llevó a la apoteosis de la industria del cine hacia el primer tercio del siglo XX. [vii]

\section{JUGUETES FONOGRÁFICOS EN LA ERA PRE-CINEMA (1900-1925)}

Previo a ese momento de conjunción tecnológica (fotografía-sonido-cinema), existe un breve período intermedio de transición, en el cual el fonógrafo desempeñó un papel social importante, constituyéndose en centro de entretenimiento principal público y familiar. Dicha experiencia de entretenimiento no se limitó al disfrute de grabaciones sonoras, musicales o de otros géneros, sino que, como veremos, se desarrolló una peculiar conjunción de experiencias auditivas y visuales a través de la integración y adaptación de juguetes ópticos y mecánicos (autómatas) al aparato fonográfico. La evolución de los llamados "juguetes fonográficos" (el término en inglés es "phonotoys"), va desde la adaptación de antiguos juguetes ópticos manuales (tales como el zoótropo o el praxinoscopio), hasta el desarrollo de diversas figuras mecánicas, cuyos movimientos eran accionados por el propio mecanismo interno del fonógrafo. 

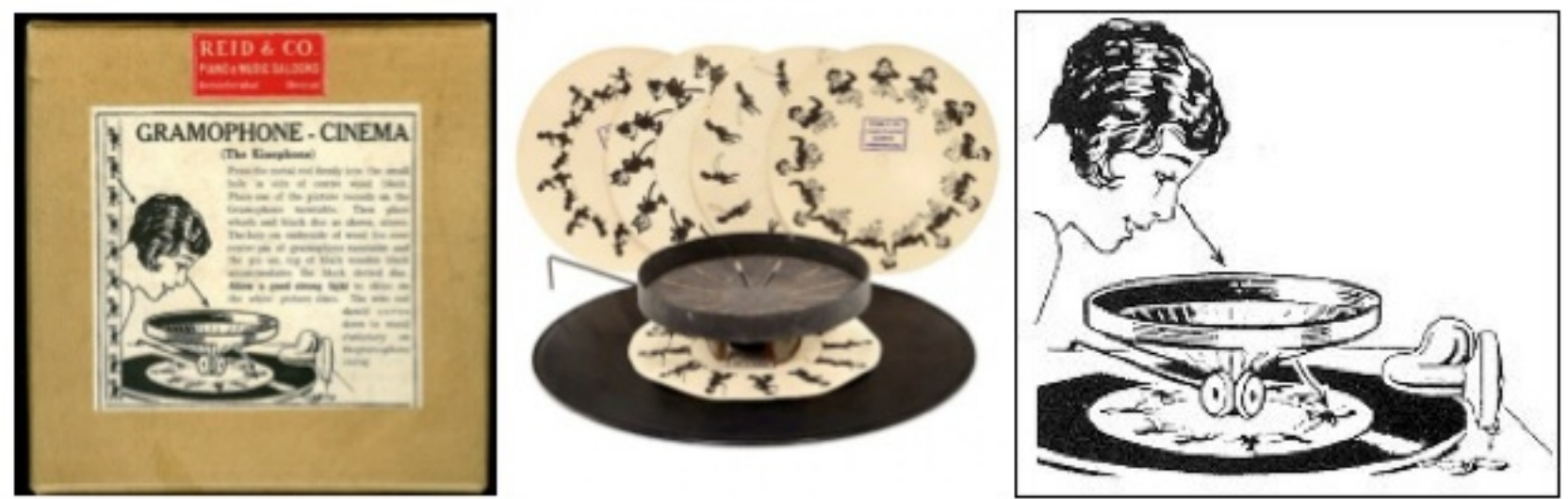

EI GRAMOPHONE-CINEMA o kinephone (ca. 1920), manufacturado y distribuido por la compañía inglesa Reid \& Co., es una variante de zoótropo adaptado para uso en un fonógrafo. El mismo provee cinco (5) discos de cartón blanco con dibujos en serie los cuales se colocan sobre el plato del fonógrafo. Sobre éstos se coloca un carrete de ruedas y una base redonda con las aperturas correspondientes, a través de las cuales el espectador puede visualizar la ilusión de movimiento perpetuo de las figuras utilizando el movimiento giratorio del fonógrafo (colección del autor).

Esta combinación particular de medios auditivos y visuales - integrados en un aparato de uso familiar y cotidiano como el fonógrafo - significó una nueva experiencia social cuyos efectos no se limitan al entretenimiento pasajero, sino que aportan al desarrollo gradual de una mentalidad mediática nueva, una que fue adaptando y modificando la percepción de la languideciente sociedad victoriana, hacia los albores del naciente medio cinematográfico. El investigador Jacob Smith (2012), establece la importancia de analizar con mayor profundidad el impacto y aportación de los juguetes fonográficos, tanto en el desarrollo de una cultura visual pre-cinema en específico, como en los procesos más amplios de alteridad y representación respecto a raza y género. [viii] Smith postula que, contrario a la noción generalizada de que las caricaturas animadas sonoras fueron el único predecesor tecnológico del cinema, los juguetes fonográficos constituyen un precedente sumamente importante, cuya aportación a estos desarrollos ha sido poco reconocida y hasta obviada. En su estudio Smith evidencia como varios juguetes fonográficos ópticos, muy en particular el llamado "phonoreel" titulado "Dancing Bear" (1922), antecede por varios años las primeras caricaturas sonoras de Max Fleischer, consideradas por los expertos como los únicos antecedentes inmediatos del cine sonoro. [ix]

Más allá de la adaptación de juguetes ópticos, entre 1915 al 1925 aproximadamente, varias compañías desarrollaron toda una serie de juguetes fonográficos dirigidos al mismo mercado consumidor, compuesto principalmente por familias de clase media y alta, así como clientes comerciales. Un estudio detallado de estos juguetes, considerando en conjunto sus características físicas, su propaganda comercial, e incluso la música asociada a éstos, provee información valiosa que apunta a complejos procesos de representación, los cuales como veremos no tan solo se limitan a los aspectos de prejuicios de raza o género, según correctamente apunta Smith, sino también a procesos de alteridad que incluso proyectaban y reforzaban las narrativas oficialistas respecto a diversos eventos históricos o procesos geopolíticos del momento.

Previo a nuestro análisis, es importante establecer como punto de partida la naturaleza del juguete como artefacto cultural. Aunque parecería claro el papel de los juegos infantiles en el proceso de socialización, posiblemente por ser considerados de forma simplista y limitarnos a su aspecto lúdico, persiste la noción errada de adscribir muy poca o ninguna importancia al rol cultural de los juguetes. Afortunadamente, existen diversos trabajos de investigación en torno a este tema, los cuales arrojan luz, no solo sobre la importancia genérica de los juegos infantiles y los juguetes como procesos y artefactos culturales, sino que más aún identifican ejemplos concretos del impacto de éstos sobre los valores y actitudes dentro del grupo social, así como en la interacción con otros grupos culturales. En un importante estudio sobre este tema, Pamela B. Nelson (1990) establece:

Toys, like other artifacts of material culture, can tell us a great deal about changing cultural attitudes and values, and about the exercise of power in society. Mass-produced toys are specially revealing because their designers, concerned with marketability, intentionally try to appeal to dominant attitudes and values. Since the 
toys reflect the attitudes of the dominant group, they have helped legitimate the ideas, values, and experiences of that group, while discrediting the ideas, values, and experiences of others, helping the favored group define itself as superior and justify its dominance. (Énfasis nuestro) $[\mathrm{X}]$

En su estudio Nelson analiza, a través de ejemplos concretos, la forma en que diversos grupos culturales minoritarios (afroamericanos, chinos, irlandeses, italianos, árabes) han sido objetos de discrimen, prejuicios y representaciones estereotipadas dentro de la sociedad norteamericana, por medio de juguetes fabricados y distribuidos en forma masiva desde inicios de la expansión industrial y económica de fines de siglo XIX. Los afroamericanos como objeto de burla y diversión, los chinos maliciosos y traicioneros, los irlandeses ignorantes, los judíos avaros; entre muchos otros, son valores y actitudes generalizadas de las clases dominantes que se reflejan y trasmiten de forma muy explícita en decenas de juguetes de principios de siglo XX. Nelson brinda particular atención en su estudio al impacto que representó en dicho período la aparición y popularidad de los denominados "juguetes mecánicos"; esto es, aquellos que requerían la participación activa del niño o usuario, ya fuese a través de accionar algún mecanismo de cuerda u otra acción mecánica, lo cual resultaba en una ilusión de movimiento perpetuo del artefacto. Dicha acción mecánica, casi autómata, en conjunto con la participación más activa del usuario, representó una innovación que abonó significativamente a que dichos "insultos étnicos" - citando a la autora - fuesen cada véz más atrayentes y aceptables. [xi]

Los juguetes fonográficos caen bajo esta categoría de juguetes mecánicos, ya que consistían en artefactos cuyo movimiento era accionado por medio del propio movimiento giratorio del fonógrafo. No obstante, al igual que Jacob Smith, postulamos que, aunque fuese por un período relativamemte breve (entre 1910 al 1925, aproximadamente), el impacto cultural de éstos fue mucho mayor en comparación con otros juguetes convencionales, dado al fenómeno sui generis de combinar, en una misma experiencia, la estimulación visual, mecánica y auditiva. En un período que precedió por pocos años el nacimiento de la experiencia cinemática; los juguetes accionados por fonógrafos - en conjunto con las primeras grabaciones musicales - aportaron significativamente, no solo al desarrollo de la incipiente sociedad del espectáculo, sino que en el proceso reforzaron esquemas valorativos y actitudes afines a las clases dominantes.

Uno de los primeros y más impactantes ejemplos es la muñeca mecánica llamada "SIAM SOO" (ca. 1917), manufacturada por la compañía de juguetes Morton E. Converse \& Son, de Winchendon, Massachusetts, y distribuida por la Columbia Graphophone Co. Siam Soo es considerada posiblemente como el más raro y complejo juguete fonográfico jamás diseñado. También es un perfecto ejemplo de los procesos de prejuicio y alteridad estereotipada ya mencionados. En Siam Soo vemos un intrincado conjunto de elementos visuales, textuales y auditivos, perfectamente estructurados y mercadeados para lograr un claro efecto de fascinación cuyo objetivo, como transluce con bastante claridad, estaba dirigido más allá del mercado puramente infantil (enlace: https://www.youtube.com/watch?v=G1iY_ZZZ6Cl). 


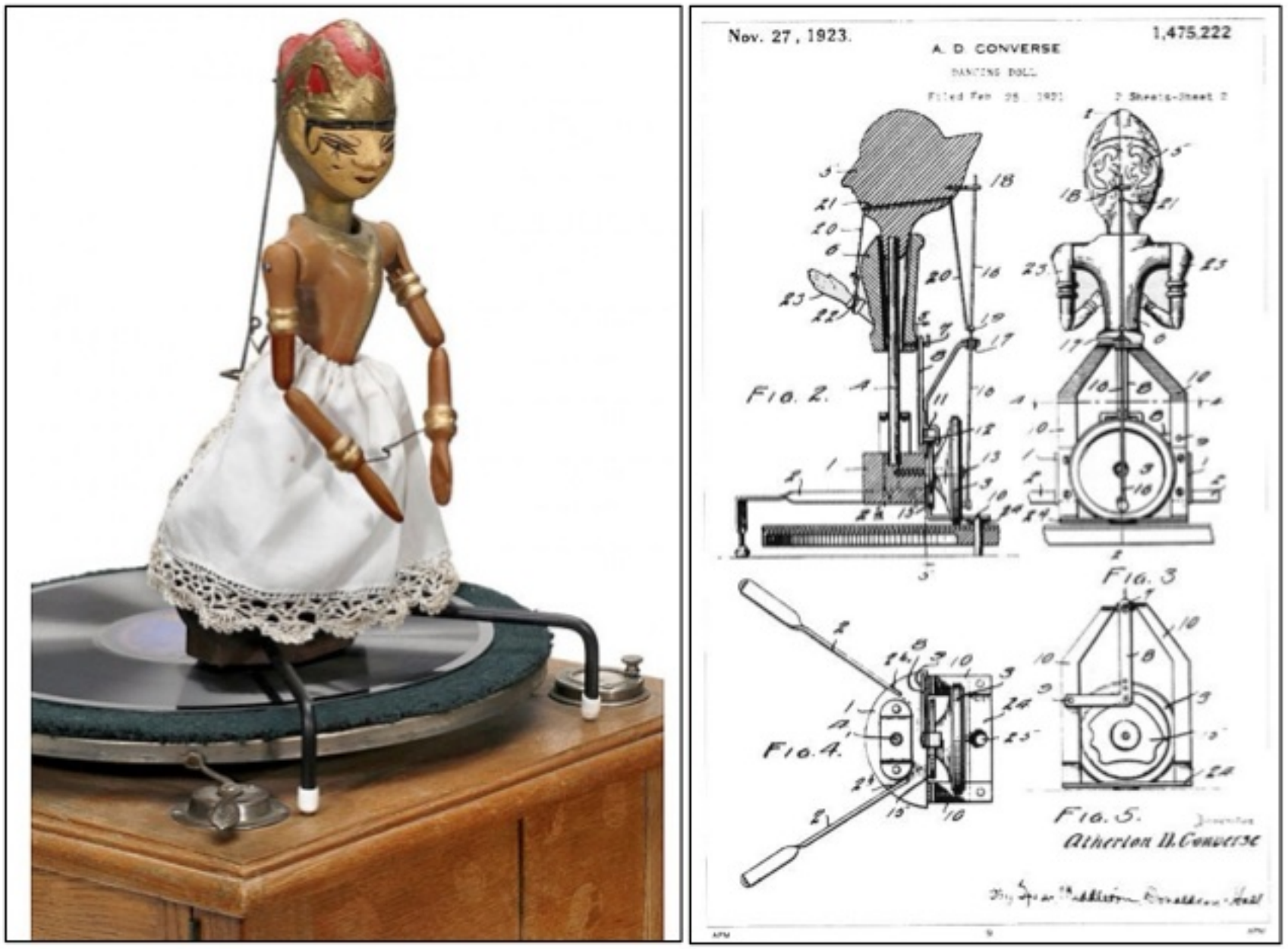

\section{IZQUIERDA: Muñeca fonográfica SIAM SOO (Morton E. Converse \& Son, ca. 1917). DERECHA: Mecanismo interno de Siam Sooo (solicitud de patente fechada en 1923).}

Siam Soo consiste de una especie de marioneta de madera diseñada para representar una bailarina de la corte del rey de Siam (hoy Tailandia). La muñeca es colocada justo al centro del fonógrafo. Bajo su falda esconde un mecanismo el cual es accionado por el movimiento giratorio del fonógrafo, produciendo un movimiento sincopado y polirítmico, el cual está supuesto a imitar el baile típico siamés. El origen, creación y mercadeo de Siam Soo es muy interesante, ya que está claramente insertado en la gran infusión y prevalencia de la tendencia orientalista que influenció a la sociedad norteamericana desde finales de siglo XIX hasta bien entradas las primeras décadas del siglo XX. En su seminal trabajo sobre este tema, Edward Said (1978) disecta los orígenes, manifestaciones y formas en que el orientalismo ha influenciado y más aún determinado la percepción que sobre dichas sociedades aún prevalecen en las sociedades occidentales o euroamericanas.

Said establece:

Orientalism can be discussed and analyzed as the corporate institution for dealing with the Orient - dealing with it by making statements about it, authorizing views about it, describing it, settling it, ruling over it: in short, Orientalism as a Western style for dominating, restructuring, and having authority over the Orient. [xii]

En su estudio, Said identifica varias acepciones definitorias y descriptivas del paradigma orientalista. Más allá de la clásica definición como campo académico o erudito (representado a través de los eminentes departamentos de estudios "orientales" o las llamadas "antiquities" que afloraron - y aún sobreviven - en la mayoría de las universidades europeas), el orientalismo toma una presencia mucho más subyacente e influyente en el pensamiento eurocéntrico, en la forma del estereotipo, de los prejuicios, de las ideas e imágenes predefinidas sobre lo que se supone define lo "oriental", esto es, los procesos de alteridad o representación del otro:

Orientalism... whose dimensions take in such disparate realms as the imagination itself...a complex array of "oriental" ideas (Oriental despotism, Oriental splendor, cruelty, sensuality)... [xiii] 
Orientalism as a body of ideas, beliefs, clichés, or learning about the east...the distillation of essential ideas about the Orient - its sensuality, its tendency to despotism, its aberrant mentality, its habits of inaccuracy, its backwardness... [xiv]

Aún al día de hoy, cuando el "occidental" piensa en aquello que es "oriental", su mente se remite a nociones de misticismo, misterio, sensualidad, erotismo; una mezcla de esplendor, riquezas y atraso, más que material, moral. Aunque el "orientalismo", como complejo proceso de alteridad respecto a las sociedades afro-asiáticas, es un fenómeno multi-centenario cuyos orígenes remontan desde la época de la ilustración (finales de siglo XVIII), en el caso de la sociedad norteamericana en particular tuvo su apogeo a partir de finales del siglo XIX. Naomi Rosenblatt (2009) analiza el desarrollo del orientalismo y su influecia en multiples aspectos de la cultura norteamericana, desde finales del siglo XIX hasta el presente. [Xv] Rosenblatt establece que los inicios de la influencia orientalista en los Estados Unidos (EEUU) se identifica con mayor fuerza y de foma muy patente a partir de las grandes ferias o exposiciones de finales de siglo e inicios de soglo XX. [xvi] Como secuela e influencia de los recuentos de viajeros y las nociones judeo-cristianas imbuidas en la sociedad Victoriana, gradualmente se desarrolló una correlación de "lo oriental" con conceptos de romanticismo, misterio y barbarie. Coincidiendo con el surgimiento de la nueva clase media consumerista, el interés y curiosidad llevó al rápido desarrollo de una "estética oriental" - unos patrones o cánones relativos a lo oriental, los cuales permearon todos los ámbitos sociales, incluyendo la arquitectura, la vestimenta, la pintura, la música, y que incluso influenciaron de forma decisiva la temática fílmica en la etapa inicial de la industria cinematográfica. [xvii]

Siam Soo ejemplifica a cabalidad los rasgos esenciales de la estética orientalista de éste período, sobre todo aquellos relativos al misterio, la sensualidad y el erotismo adscrito al género femenino oriental. Como bien indica Said; el orientalismo es en esencia un ámbito de dominio masculino, en el cual la mujer se concibe como una "criatura de fantasia y poder", de "sensualidad ilimitada, más o menos estúpida y siempre deseosa" (traducción nuestra). [xviii] Rosenblatt amplia este aspecto en su estudio del impacto de las exhibiciones orientalistas de las ferias de fines y principio de siglo sobre la sociedad Victoriana: "In the public imagination, the Orient became linked with the sexualized belly dancers, luxurious temples and obelisks...". [xix] Más allá del obvio aspecto físico, en el cual se personifica una bailarina siamesa, Siam Soo está complementada por todo un andamiaje textual, una narrativa sobre su origen que nos remite a una fantasia muy elaborada sobre la corte del rey de Siam, su harem (concepto de origen árabe, aquí aplicado arbitrariamenmte) y los efectos sensuales y eróticos que dicha bailarina causaba en todos los que la obserbaban. Dicho texto se encontraba impreso en la caja de cartón que servía de empaque para el juguete. Para legitimar la veracidad del relato, así como la supuesta corrección y verosimilitud de la muñeca con respecto a su referente original, el empaque incluye el siguiente narrativo:

An American traveler in Siam visited the King's Harem and was attracted by the unusual motions of the King's dancers. A model was made by a Siamese toy maker and adapted by Morton E. Converse \& Son Company to play on the Columbia Grafonola - or any other disc phonograph.

The dancers in the King's Harem have their necks gilded to indicate royalty and their faces are covered with heavy paste to conceal any facial emotions, thus depending solely on the motions of the dance.

Siam Soo is true to all these details and the motion of her dancing is strikingly similar to that of the Royal Siamese Dancers in the King's Harem.

Esta última línea establece el elemento más importante y crítico en el impacto experiencial de Siam Soo; esto es, su adscrita capacidad de reproducir con fidelidad los movimientos de las bailarinas de la corte siamesa. Es innegable que los creadores de Siam Soo capitalizaron en el aspecto sensual y erótico de dichos movimientos. La frase publicitaria (slogan) que identifica la muñeca en el empaque establece, de forma exclamativa: "Siam Soo. She Puts the Oh - Oh in Graf-o-nola". Es interesante observar que en la tipografía del empaque, todas las letras $O$ en dicha frase están dibujadas como caras sonrientes, reforzando el efecto sensorial y lúdico del baile sobre el espectador. 


\section{SIAM Soo \\ She puts the $\mathrm{O}_{\pi} \mathrm{O}_{1}$ in Graf-onola}

Como hemos indicado, Siam Soo es sin dudas el más raro y complejo juguete diseñado para su uso en el fonógrafo. De hecho, Siam Soo presenta un nivel de sofistificación adicional único que no comparte con ningún otro juguete fonográfico, ya que como parte de la estrategia publicitaria y de mercadeo, la Columbia Graphophone Co. incluyó una extensa lista de grabaciones fonográficas, claramente identificadas como de corte "oriental", y las cuales se ofrecían a la venta para complementar el baile de la muñeca. Dependiendo el modelo de la muñeca, [xx] el empaque incluía una lista de entre 28 a 36 títulos de canciones de temas especialmente escogidos para éste propósito. Según expone Ulises Beato, la mayoría de dichas selecciones combinaban el emergente género del jazz con un claro énfasis en el estilo oriental. [xxi] Este elaborado esquema combinado de mercadeo tuvo su culminación en 1921, cuando la Columbia lanzó un disco exclusivamente diseñado para Siam Soo, conteniendo en su lado A la canción homónima, escrita por Sidney F. Lazarus, con música de Otto Motzan y M.K. Jerome, e interpretada por el conjunto The Happy Six. Un análisis de la letra de Siam Soo evidencia de inmediato los elementos tradicionales del discurso orientalista estereotipado, realzando claramente diversas instancias en que se enfatizan los elementos de misterio, erotismo, sensualidad, sexismo y poder, desde el punto de vista masculino. La canción consta de ocho (8) estrofas, de las cuáles reproducimos algunas a continuación:

\section{SIAM SOO}

In Siam, where strange things they do,

there lived a girl named Siam Soo,

Who shooked a wicked shoulder when she danced.

She had the cutest jiggle,

and when she'd start to wiggle,

She'd put the men around her in a trance.

Siam Soo, Siam Soo, she makes the men

so nervous it's a shame.

She kept four Kings in waiting,

While she was syncopating.

\section{She was so fascinating that the men}

\section{where not to blame.}

She was full of vim and vigor,

And goodness, what a figure,

Men looked at her and then forgot to eat.

With a strange Egyptian shiver,

She would make each muscle quiver. 
(énfasis nuestro) [xxii]

La combinación súmamente estructurada de los elementos físicos (movimiento polirítmico), visuales (fisionomía, vestimenta, colores) y auditivos (ritmo de fox-trot, letra de narrativa fantasiosa e insinuaciones sensualistas), hacen de Siam Soo uno de los mejores y más sofisticados ejemplos del impacto cultural de los juguetes mecánicos fonográficos en la perpetuación y difusión de estereotipos y discursos de alteridad, en este caso, dentro de las corrientes del orientalismo que caracterizó la sociedad norteamericana a inicios del siglo XX. [xxiii]

Mientras en Siam Soo encontramos un sofisticado entrejuego, casi subliminal, de insinuaciones y estereotipos velados, otros juguetes fonográficos - a igual que la generalidad de los juguetes convencionales de la época proyectan prejuicios y estereotipos de forma mucho más directa, principalmente dirigidos a las minorías afroamericanas. En esta dirección, una de las principales compañías manufactureras de juguetes fonográficos fue la National Toy Company, establecida en Boston, Massachussets. Esta empresa fue fundada entre 1910 al 1914, originalmente bajo el nombre de National Company, por tres ingenieros que laboraban en la naciente industria de generación eléctrica. Warren Hopkins, Rosewell Douglas y Walter Balke trabajaban para la compañía Stone and Webster Co., empresa dedicada a la construcción de plantas generadoras de electricidad. Estos se independizaron y establecieron su compañía, dedicada a suplir transformadores y otros equipos para la nueva industria de electrificación. No obstante, en un período de inactividad y baja en los pedidos, los socios decidieron diversificar la empresa, adaptando sus equipos y líneas de producción para la fabricación de otros productos que tuviesen demanda. Es aquí que identifican el mercado de los juguetes, generando toda una exitosa línea de juguetes mecánicos, adaptados para su uso con otro producto de creciente demanda y popularidad: el fonógrafo.

En octubre de 1914 reincorporaron la compañía bajo el nombre de la National Toy Company. Su primer juguete fonográfico fue "RAGTIME RASTUS" (ca. 1915). Rastus consistía de una marioneta de madera de un personaje negro, la cual se colocaba en una plataforma sobre el fonógrafo. La parte inferior de la plataforma contaba con un mecanismo el cual era accionado por el movimiento giratorio del plato, lo cual tenía el efecto de hacer saltar la marioneta por medio de un alambre en su parte inferior. La acción de saltos rítmicos, unida a la música del fonógrafo, daba la impresión de que el muñeco bailaba al compás del mismo. Rastus fue un rotundo exito, dando paso a toda una serie de variaciones temáticas haciendo uso del mismo mecanismo. Los juguetes eran distribuidos por establecimientos comerciales tales como F.A.O. Schwarz, Woolworth, Jordan Marsh, Gimbels, y en especial a través de las tiendas distribuidoras de fonógrafos, tales como las de la Victor Talking Machines y la Columbia Graphophone Co., principales líderes en este mercado. Tan solo entre enero y junio de 1916, la National Toy vendió unos 8,800 de estos juguetes, y planificaba producir otras 16,000 unidades para el resto del año. [xxiv] 


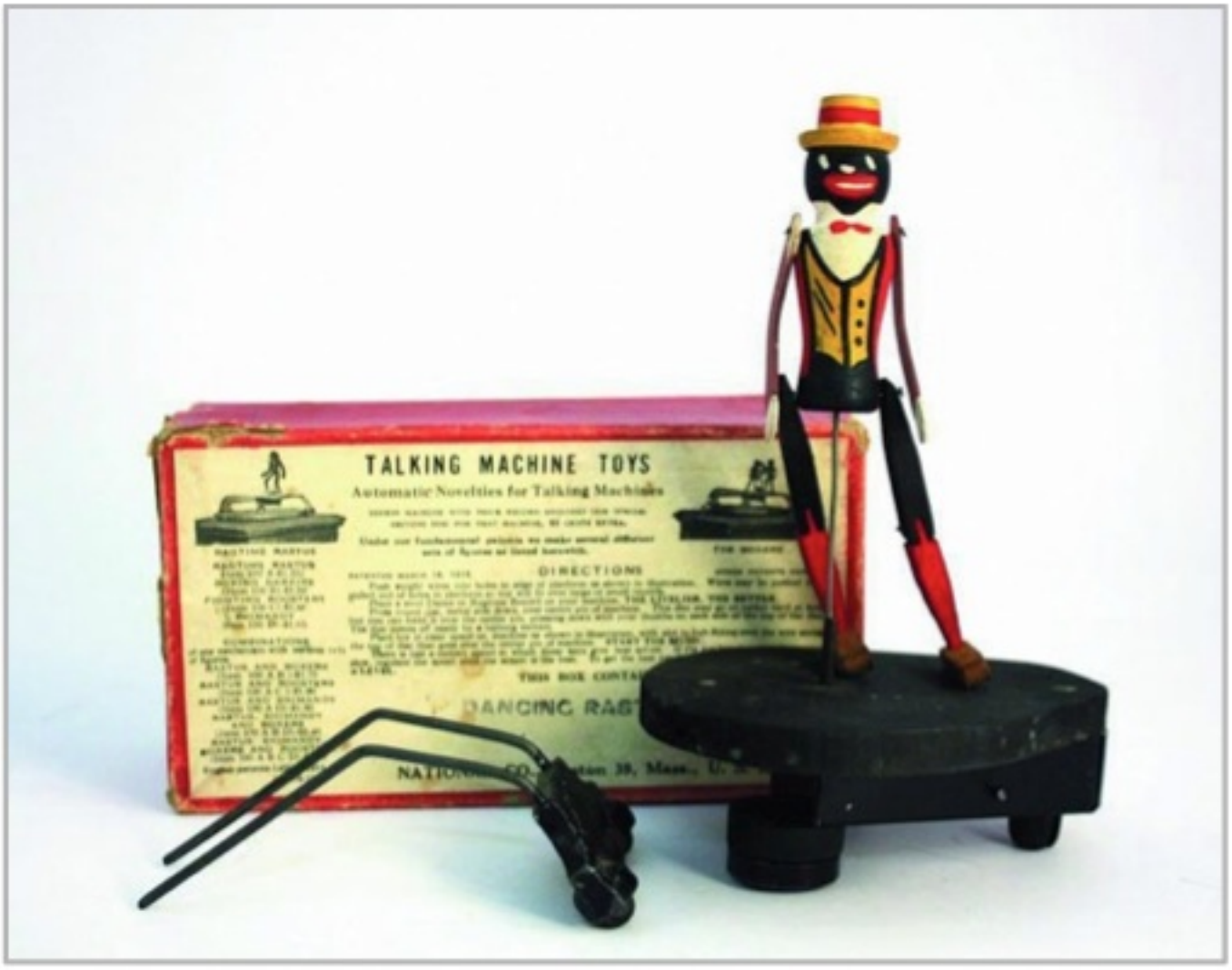

"Ragtime Rastus", National Toy Co. (ca. 1915)

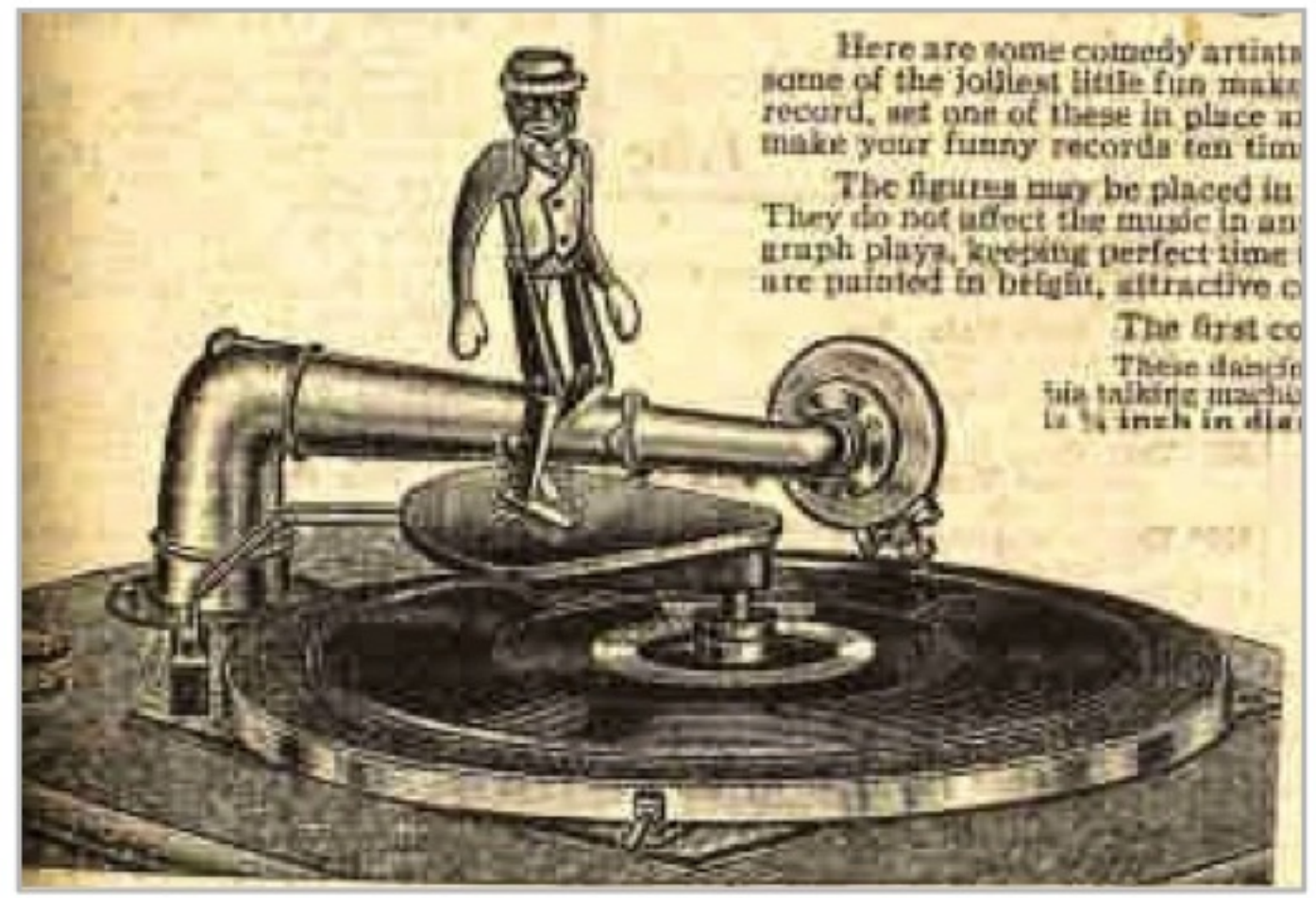

Anuncio de "Ragtime Rastus" en el catálogo de la Sears Roebuck and Co. (ca. 1917)

Ragtime Rastus es sin dudas, no solamente el juguete fonográfico de mayor exito y popularidad del período (entre 1915 al 1925 aproximadamente), sino también el más claro ejemplo de prejuicio y patente racismo entre todos los juguetes de su tipo. Al igual que muchos otros juguetes de corte racista de la época - y contrario al caso de Siam Soo - estos prejuicios no son velados o disimulados. [xxv] El propio nombre "Rastus" es una expresión racista y peyorativa, aplicada a hombres negros, cuyo origen remonta hacia el 1880. El nombre "Rastus" designa al estereotipo peyorativo del "negro feliz"; aquel personaje que con el tiempo vino a 
popularisarse como objeto de burla en las rutinas de vaudeville conocidas como "black minstrels" o "coons". En estos espectáculos, hombres blancos se pintaban el rostro de negro y parodiaban en tono burlón y ofensivo los ademanes, gestos y expresiones verbales de los negros. [xxvi]
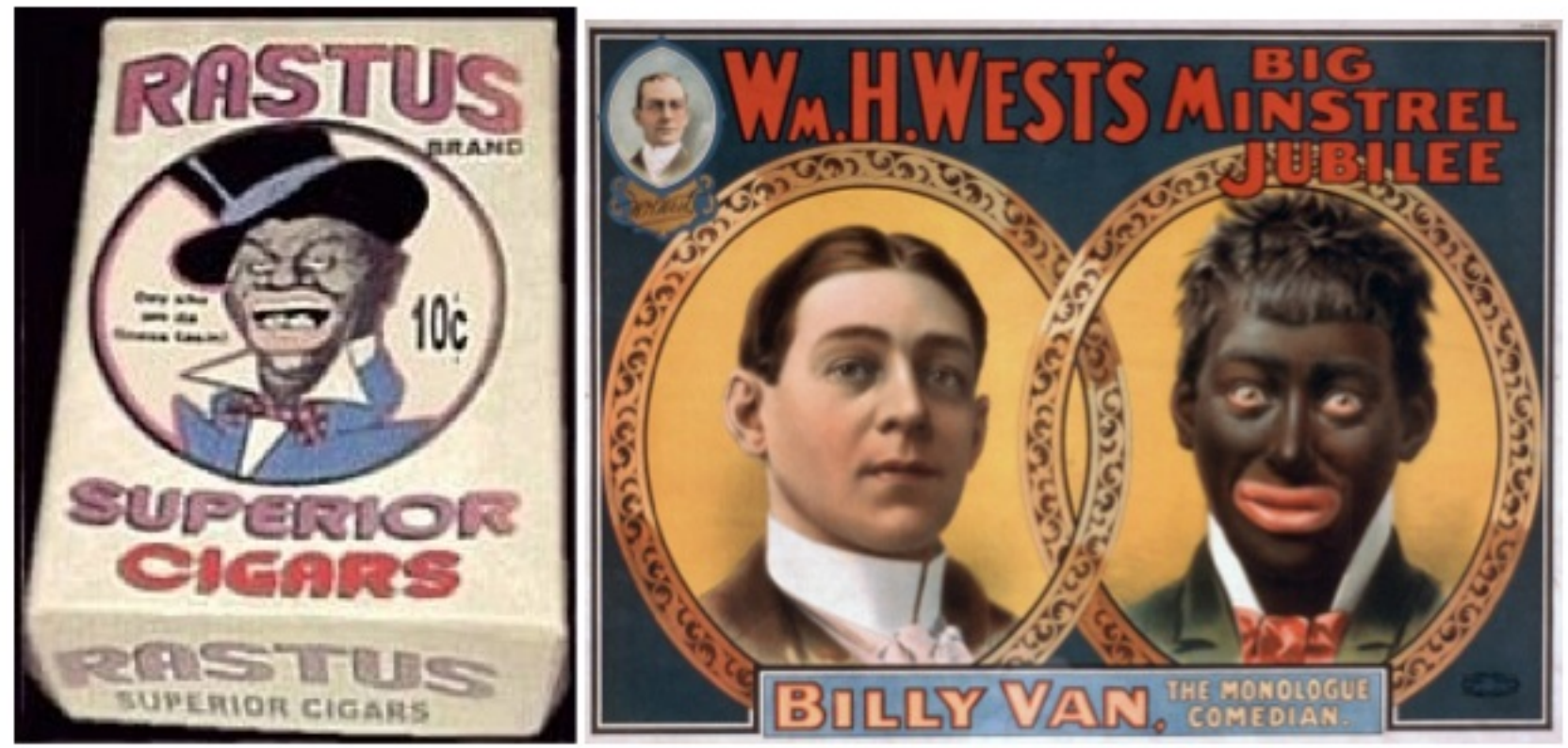

Un anuncio del catálogo de Sears Roebuck (ca. 1917, próxima página), comunica de forma muy natural este tipo de expresiones racistas y el estereotipo del "negro cómico", aceptado como normal en las clases medias norteamericanas de principio de siglo: Here are some comedy artists worth watching...Ragtime Rastus - One of the funniest dancing figures ever made. Rastus is the original ragtime coon...(énfasis nuestro).

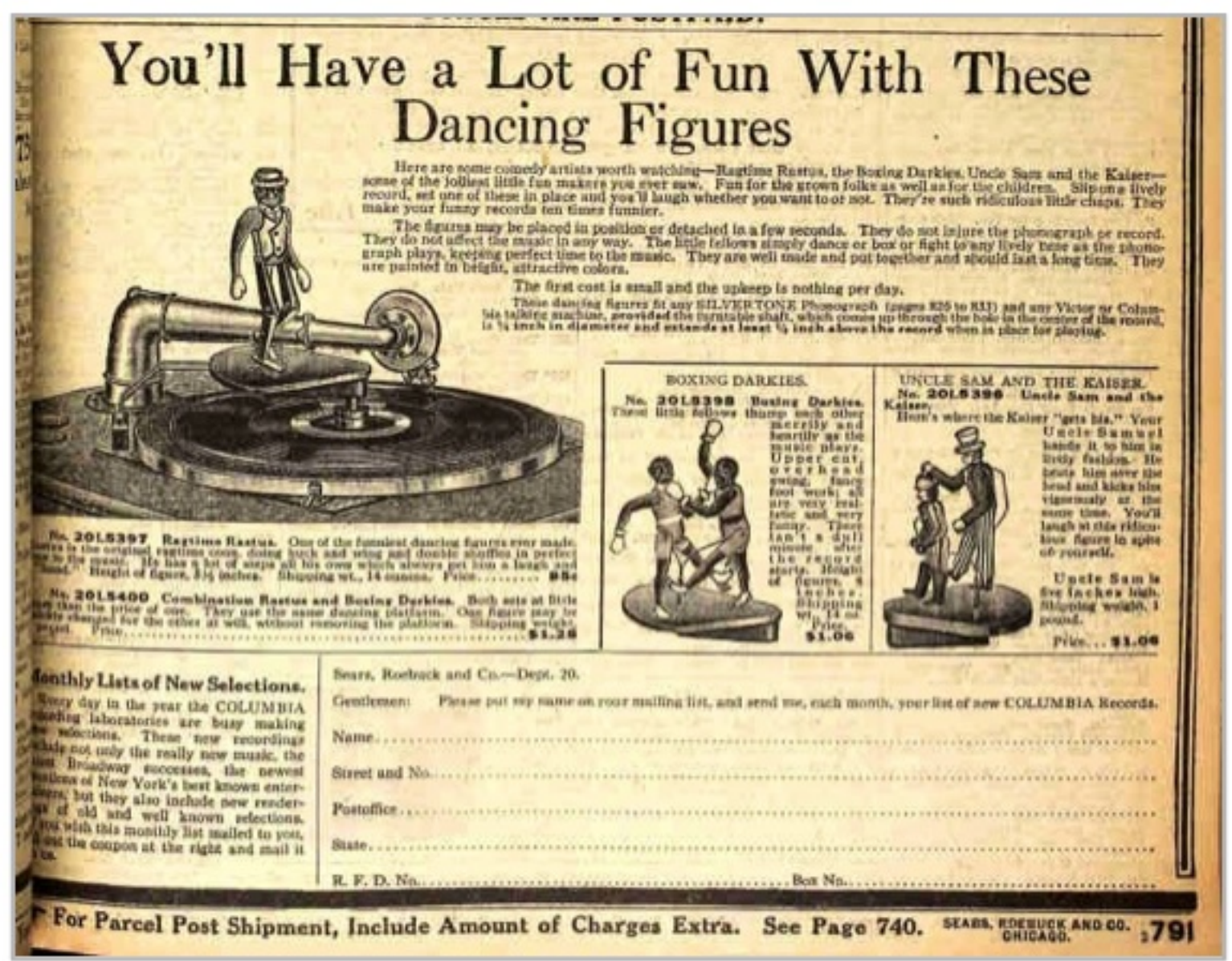

Anuncio de la National Toy Co. publicado en el catálogo de Sears Roebuck and Co. (ca. 1917)

Todavía a la altura de 1922, en un pequeño folleto promocional inluido en el empaque de otro de sus juguetes 
fonográficos ("The Magnetic Dancers"), "Ragtime Rastus" era promocionado en conección con la cultura de la plantación esclavista y como fiel reflejo del "black minstrel": "Ragtime Rastus" is an automatic dancing darky who faithfully imitates the old time plantation dancer" (énfasis nuestro). (Enlace:

https://www.youtube.com/watch?v=Vlid6MHVNvA).

Rastus era mercadeado de forma individual a un costo de $\$ 1.25$, o en combinación con otras figuras a un costo de $\$ 1.75$, las cuales se usaban con la misma plataforma accionada por el fonógrafo. La más popular de estas combinaciones o juguetes complementarios era una pareja de boxeadores negros, distribuidos bajo el nombre de "Boxing Darkies" (véase anuncio de Sears Roebuck). Además de este nombre peyorativo, al igual que Rastus la pareja de boxeadores tenían sus rostros pintados para exagerar los gestos típicamente asociados al "dancing coon"; gruesos labios rojos, gran sonrisa blanca en contraste con la piel negra y grandes ojos saltones (enlace:https://www.youtube.com/watch? $v=$ TCGov3hJulM).
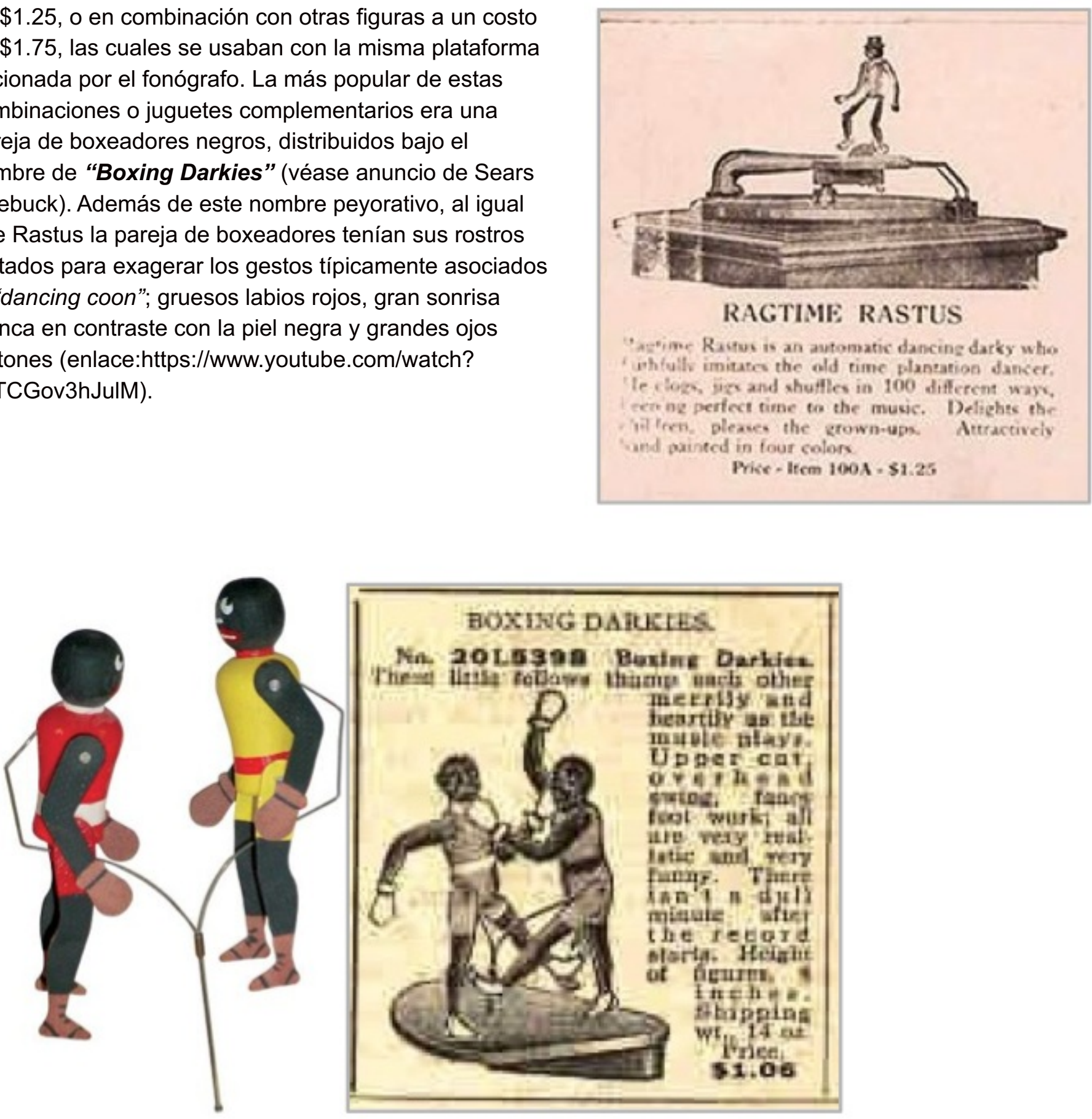

IZQUIERDA: "Boxing Darkies", National Toy Co. (ca. 1915).

DERECHA: Anuncio de los "Boxing Darkies", catálogo de Sears Roebuck (ca. 1917).

Posiblemente en respuesta al exito de la muñeca Siam Soo, la National Toy Co. produjo a "Shimandy", una especie de complemento femenino a Rastus. El nombre deriva del térmno "shimming" o "shimmer", relativo al temblor, movimiento o vibración rítmica de la muñeca al bailar. Shimandy continua la línea estereotipada y racista de Rastus, buscando capitalizar el elemento de comicidad en la figura de una mujer negra, que salta al son de la música, ataviada de un traje colorido. En el mismo folleto de 1922, Shimandy se presenta como la "hermana" de Rastus; y más allá del elemento racial y de comicidad, la descripción resalta un elemento de sensualidad y erotismo: "She successfully portrays the colored belle in her most ecstatic moment. Her dance is entirely different from Rastus. She is delightfully humorous and pleasing to everyone" (énfasis nuestro). La 
alusión sexista vá más allá de ser una generalizada, sino que está implícito un atributo o particularidad de "extasis" sensual de la "bella de color". Nuevamente, un artefacto de cotidianidad, cuyo objetivo explícito se justifica en la diversion y entretenimiento, se convierte en un canal de difusión de prejuicios y narrativas de alteridad, que van desde un racismo peyorativo explícito, hasta insinuaciones de género ya más veladas.

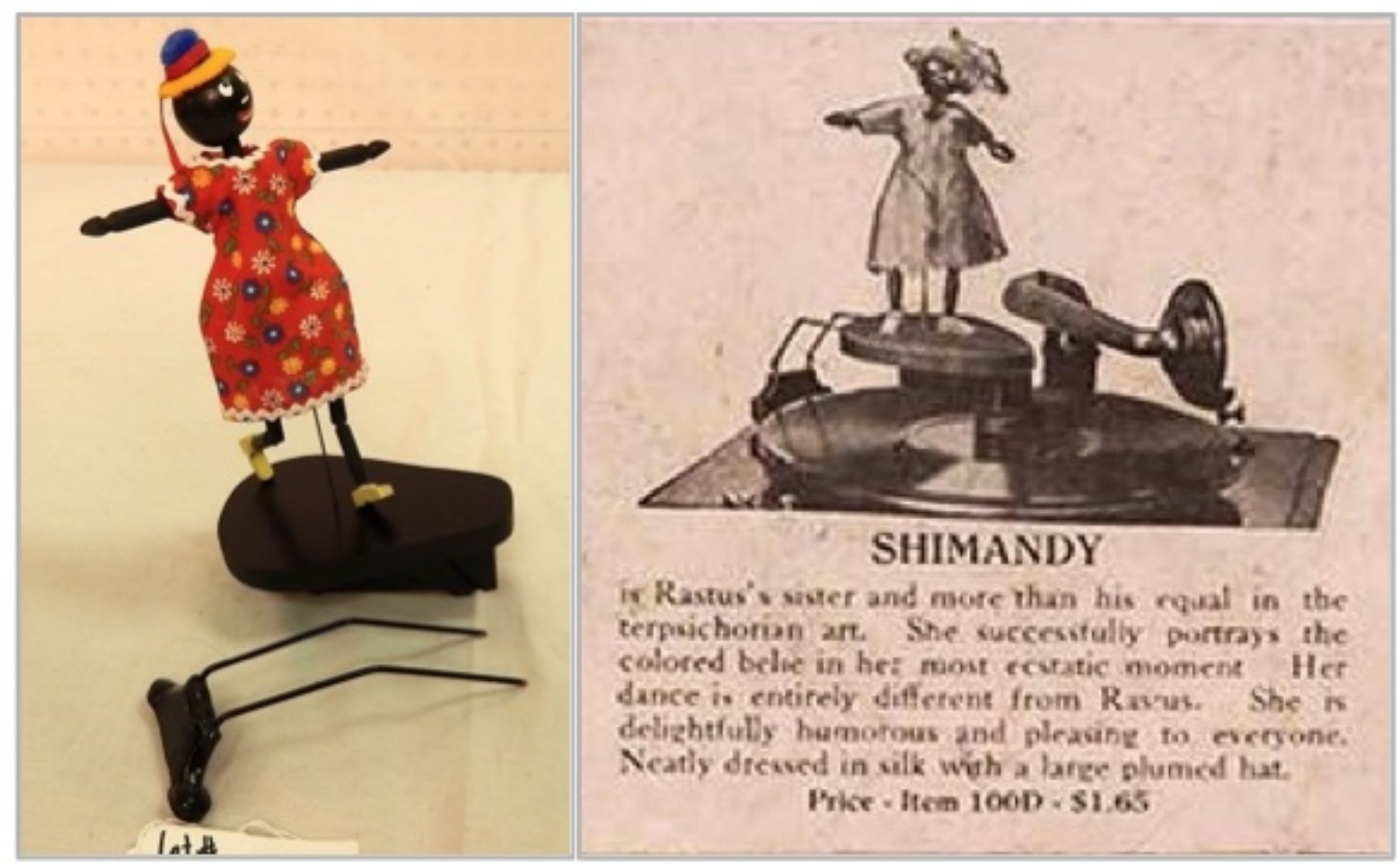

IZQUIERDA: "Shimandy", National Toy Co. (ca. 1920).

DERECHA: Descripción de Shimandy en folleto de 1922 (colección del autor)

Además de su línea principal de juguetes fonográficos de corte claramente racista (Rastus, Shimandy, Boxing Darkies), la National Toy Company también desarrolló varios juguetes similares para su uso en el fonógrafo, en los cuales capitalizaron el interés sensacionalista que permeaba en grandes sectores de la sociedad norteamericana relativos a diversos acontecimientos noticiosos. En contraste con el prejuicio racista directo, en estos juguetes encontramos un nivel mucho más sutil de alteridad; unos procesos de connotación y representación del otro; en estos casos, respecto a grupos culturales externos considerados enemigos de los intereses de la sociedad norteamericana en general, o de sus élites de poder.

Con la entrada directa de los EEUU en la Primera Guerra Mundial en 1917, a través de toda la nación se desató una ola de prejuicio y hostilidad en contra de la creciente población de inmigrantes de origen alemán. [xxvii] Al igual que en otros momentos históricos similares, la opinión pública - movida por la propaganda - se volcó en contra de todo aquello que se pudiese identificar como enemigo de la nación. El blanco principal de esta hostilidad lo fue el Kaiser Willhelm II, último emperador de Alemania (1879-1942), el cual personificaba todos los valores negativos que se adscribían a los alemanes, sobre todo los atributos de violencia, crueldad y ambición desmedida. Nuevamente, la prensa norteamericana no perdió tiempo en reforzar la animosidad del pueblo estadounidense en contra del Kaiser, desarrollando innumerables editoriales y caricaturas peroyativas del líder alemán. 

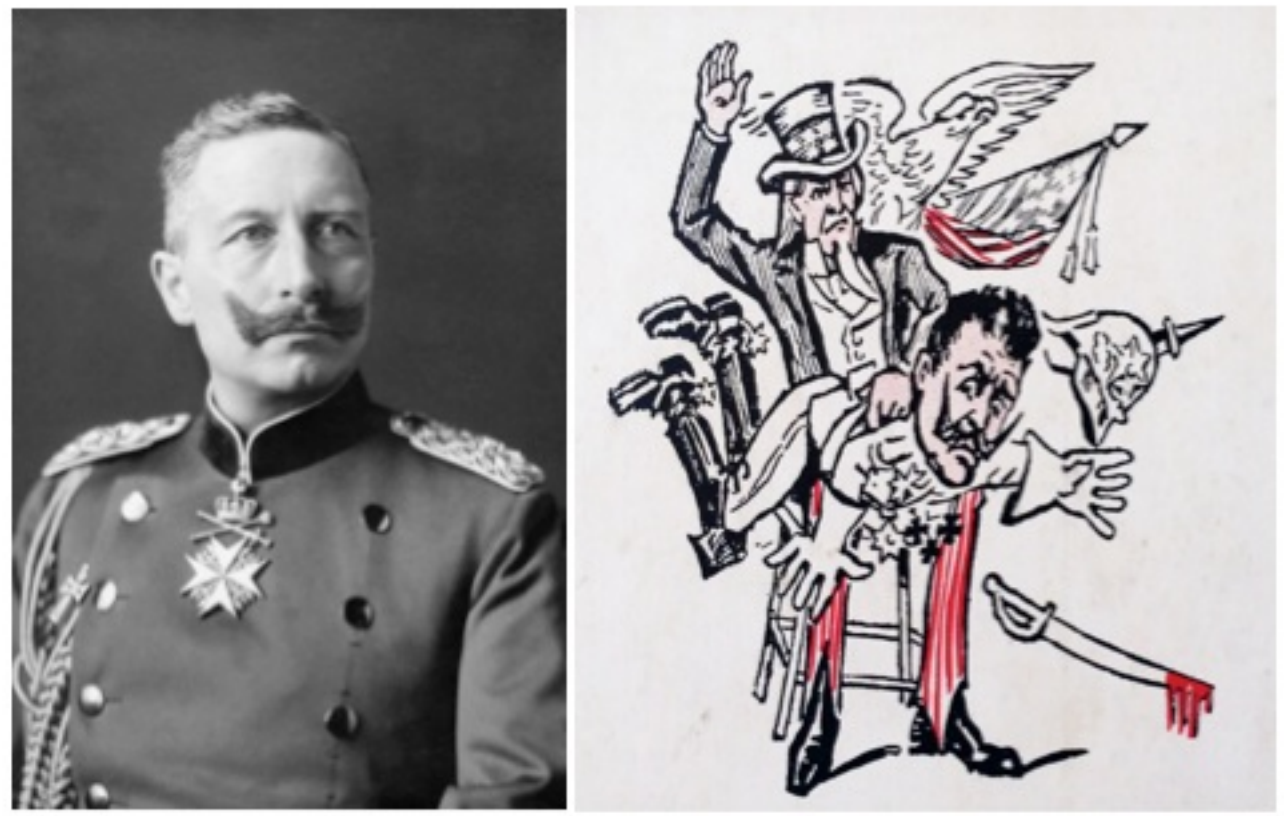

EI Kaiser alemán, Wilhelm II. Varios ejemplos de las muchas caricaturas satíricas de la prensa norteamericana durante los años de la primera Guerra Mundial.

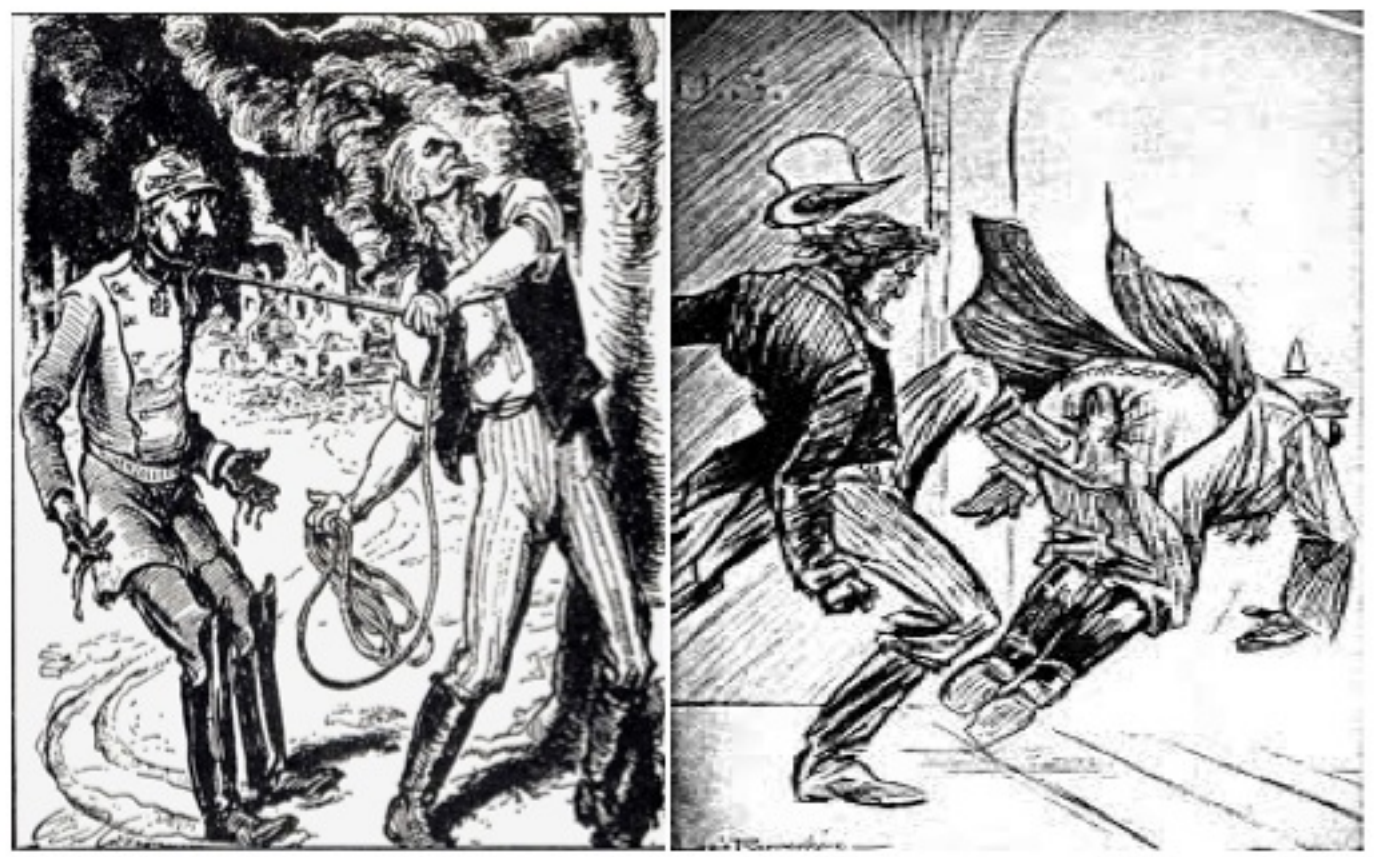

El Kaiser alemán, Wilhelm II. Varios ejemplos de las muchas caricaturas satíricas de la prensa norteamericana durante los años de la primera Guerra Mundial.

Por lo general, las caricaturas satíricas del Kaiser lo representaban siendo apresado, sojuzgado o incluso siendo objeto de violencia física (golpeado, pateado, ahorcado) por parte del "Tío Sam", ícono representativo de los valores patrióticos norteamericanos. [xxviii] La National Toy Company captalizó en éste sentimiento "antiKaiser" generalizado, y mercadeó con mucho exito un juguete fonográfico en la forma de la figura del emperador alemán siendo perseguido y pateado por el Tío Sam. El diseño presenta varios detalles importantes que abonan al efecto satírico y a la proyección de superioridad del Tío Sam (los EEUU) sobre el Kaiser (Alemania). La figura del Kaiser es mucho más pequeña, se presenta a un nivel más bajo e inclinada hacia el frente, en perfecta posición para ser pateado en el trasero. Al accionarse el movimiento en la plataforma sobre el fonógrafo se recrea una escena del Kaiser huyendo, siendo perseguido y pateado por el Tío Sam. El juguete se mercadeaba bajo los nombres de "Uncle Sam and Kaiser Bill" o "Uncle Sam kicks the Kaiser". Accionado en conjunto con discos de marchas militares y canciones patrióticas, este juguete lograba cabalmente un doble efecto de divertir, a la vez que exacerbaba los sentimientos nacionalistas y reforzaba el mensaje de alteridad y 


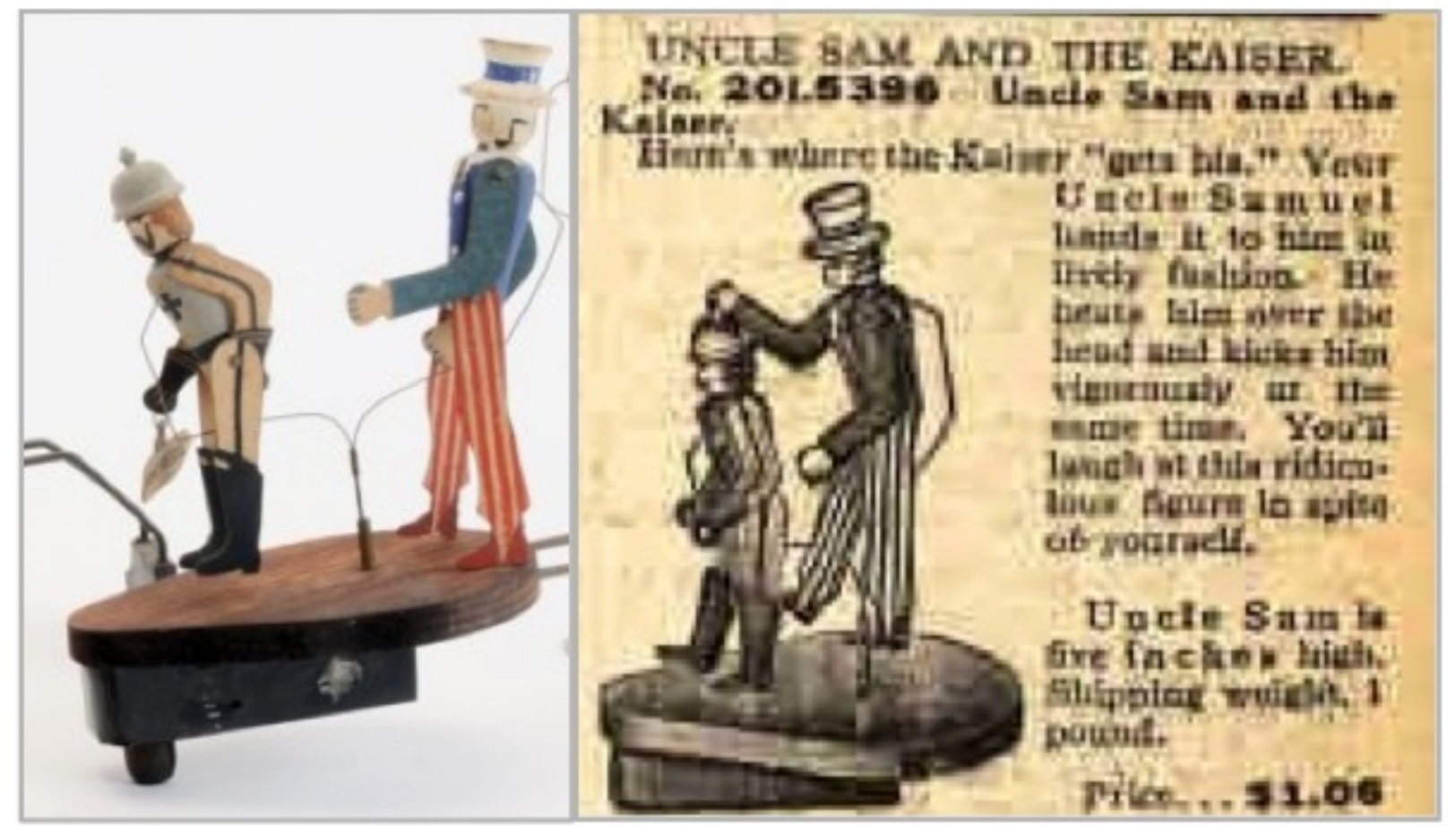

IZQUIERDA: "Uncle Sam and Kaiser Bill". National Toy Co (ca 1917). DERECHA: Anuncio en el catálogo de Sears Roebuck (1917)

El mismo mecanismo y diseño de "Uncle Sam/Kaiser Bill” fue utilizado por la National Toy Company para mercadear un juguete similar, aprovechando otra instancia de sensacionalismo y fervor nacionalista sobre eventos y personajes mucho más cercanos a sus fronteras. En 1916, el líder revolucionario mejicano Francisco "Pancho" Villa cruzó la frontera suroeste de los EEUU, atacando varias poblaciones, y en particular haciendo grandes estragos al poblado de Columbus, Nuevo Méjico. Al igual que el caso del Káiser de Alemania, la prensa del país se dio a la tarea de diseminar editoriales y partes noticiosos de corte claramente sensacionalistas, los cuales no solo estaban dirigidos a demonizar la figura de Villa, sino que de paso proyectaban múltiples mensajes negativos respecto al pueblo mejicano, su cultura y características. La figura de Pancho Villa vino a convertirse en ícono representativo del mejicano sanguinario, primitivo y, sobre todo, traicionero. Las caricaturas de la época nuevamente establecen de forma exagerada éstas y otras caracterizaciones negativas. 

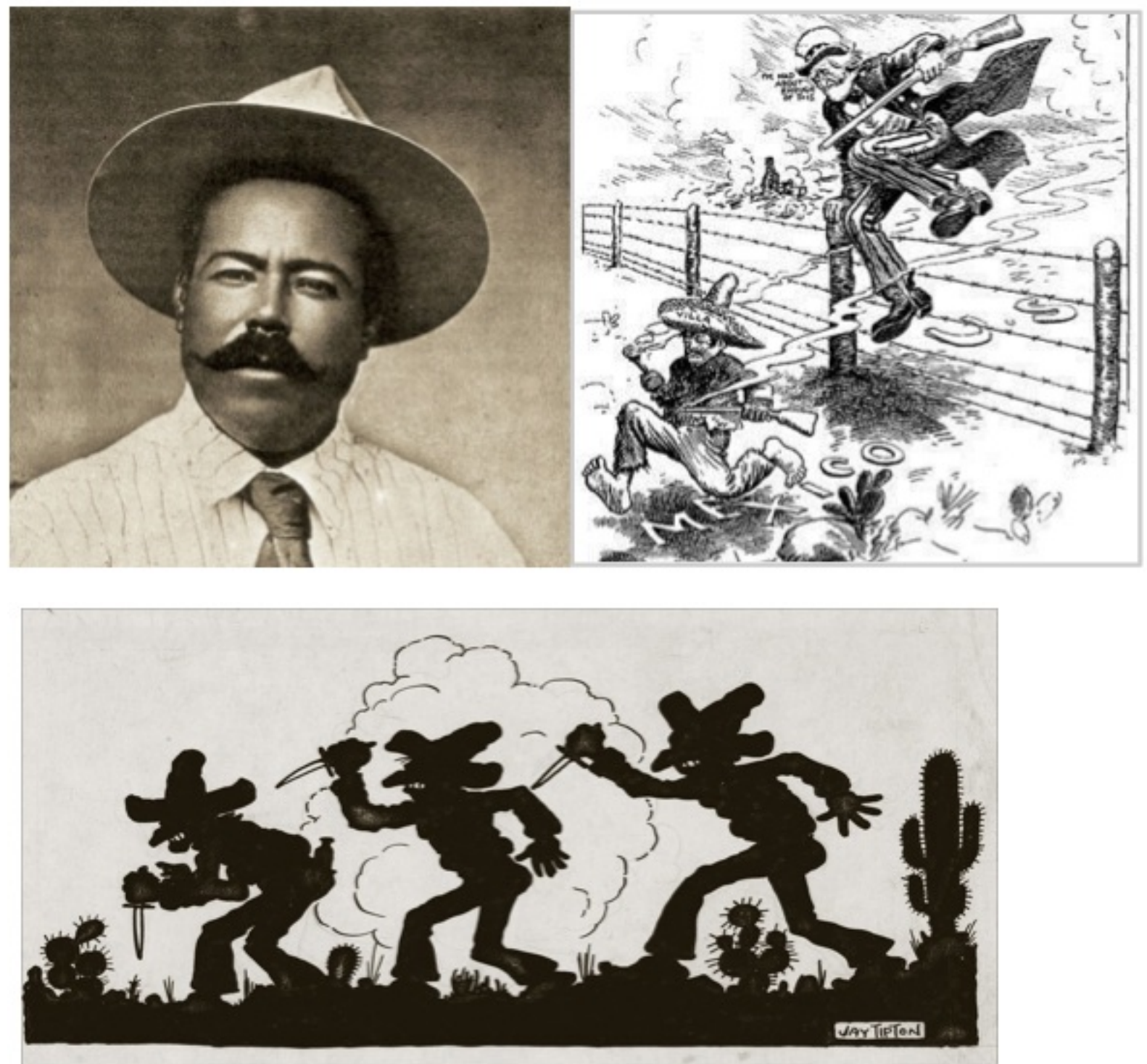

Francisco "Pancho" Villa (1878-1923). Sus incursiones en la frontera suroeste de los EEUU provocaron una oleada de opinion pública negativa, estimulada por editoriales y caricaturas sensacionalistas que caracterizaban lo mejicano como cruel, sanguinario y traicionero. 


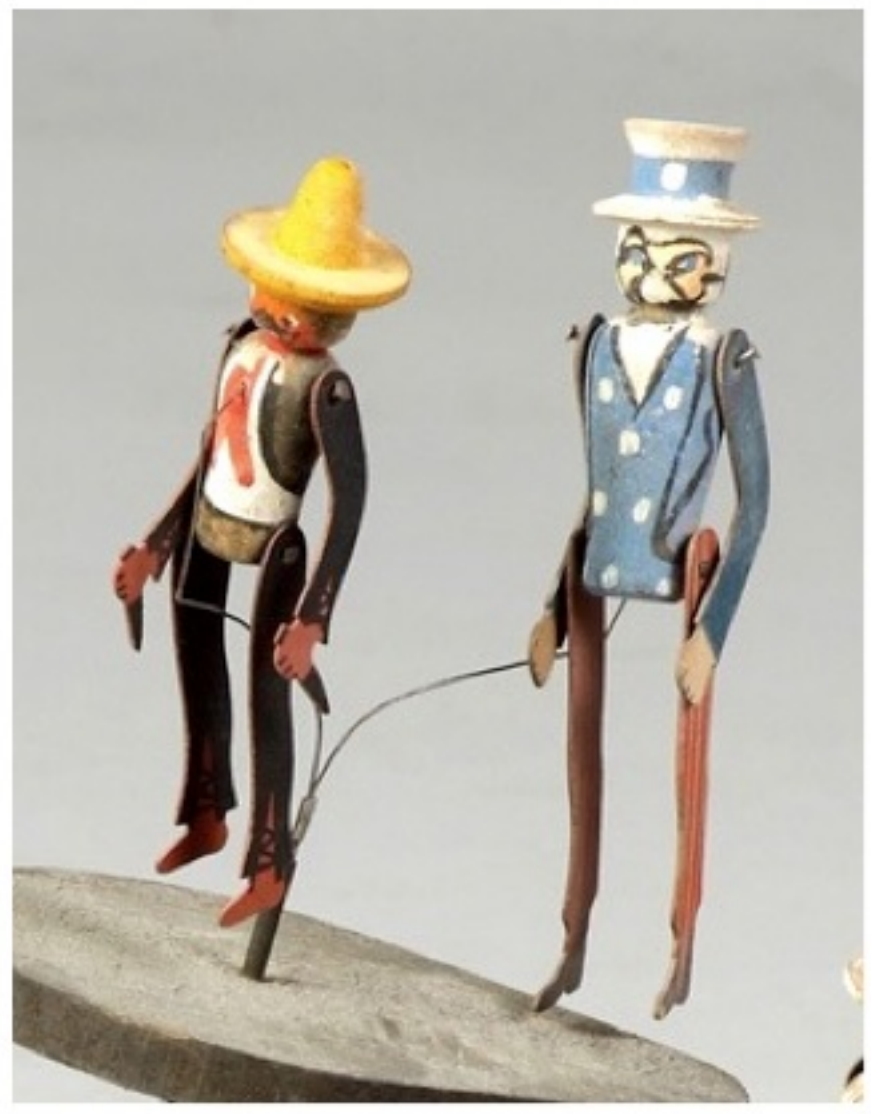

"Uncle Sam kicks the Mexican", National Toy Co. (ca. 1916)

Aprovechando la animosidad generalizada hacia la persona de Villa, así como hacia todo lo mejicano, en 1916 la National Toy Company sacó al mercado a "Uncle Sam kicks the Mexican". Al igual que en el caso del Kaiser, la figura del mejicano es mucho pequeña que la del Tío Sam, abonando al efecto satírico y a la noción de dominio y superioridad norteamericana. Para acentuar la representación estereotipada del mejicano sanguinario, la figura lleva puñales en ambas manos, elemento común a muchas de las caricaturas y representaciones gráficas de mejicanos, según presentadas anteriormente. Aunque no tenemos disponibles datos concretos sobre ventas de los distintos juguetes de la National Toy Company, este juguete es mucho más raro y escaso que el de "Uncle Sam/Kaiser Bill", por lo que posiblemente no tuvo tanta salida ni distribución como éste último. Debemos pensar que los eventos en la frontera mejicana no tenían tanto impacto nacional como las hostilidades con alemania y la entrada a la guerra europea. No obstante, aunque fuese por un breve período de tiempo, "Uncle Sam kicks the Mexican" abonó a reforzar una percepción muy negativa hacia lo "mejicano" dentro de la sociedad estadounidense de principios de siglo (enlace:

https://www.youtube.com/watch?v=ke45QJjFigk).

\section{CONCLUSIONES}

Un análisis de esta muestra de juguetes fonográficos de principios de siglo XX confirma - parafraseando nuevamente a Pamela B. Nelson - la importancia crítica de considerar los juguetes como artefactos de la cultura material de una sociedad, los cuales pueden ser sumamente reveladores respecto a sus dinámicas actitudinales, sus valores y sus estructuras de poder. [xxix] Superando las características genéricas de los juguetes "convencionales", los juguetes fonográficos presentan una combinación muy particular de elementos que, más allá de la trasmisión de simples mensajes prejuiciados, abonaron a ir desarrollando una mentalidad o perceptibilidad hacia lo mediático, sirviendo como precursores a una sociedad del espectáculo que encontraría su mayor efervescencia con la aparición posterior del cinema, la radio y la televisión. La combinación de elementos de participación del usuario por su naturaleza mecánica, la ilusión de realismo (por su naturaleza de movimiento autómata), unido a la sincronización con las grabaciones sonoras fonográficas (en ocasiones con alusiones textuales y sonoras muy estructuradas y directas, como es el caso del despliegue oriental y 
sensualista de "Siam Soo"), hicieron de los juguetes fonográficos un instrumento muy efectivo y poderoso en la modificación y desarrollo de ese nuevo entorno perceptual, con toda su agenda de impactos culturales.

Otro aspecto de suma importancia que debemos considerar es que, tanto por el precio como por la naturaleza claramente sensual y erótica de muchos de estos juguetes, es claro que los mismos no fueron intencionalmente diseñados para, ni eran comprados exclusivamente por niños. Todo lo contrario. Muñecas sensualistas como "Siam Soo" y "Shimandy", o juguetes de claro corte político como "Uncle Sam" y el Kaiser o el mejicano (Pancho Villa), estaban pensados para un mercado adulto y masculino, con suficiente capacidad adquisitiva para invertir el equivalente de dos o tres días de salario promedio en estas nuevas amenidades. [xxx]

Coincidimos con Jacob Smith cuando resume la forma en que estos juguetes fonográficos establecían todo un nuevo entorno experiencial: When experienced in tandem with records such as these (grabaciones, sonidos, canciones, bailes) phonotoys created a semiotic admixture of racial caricature, modern musical genres, and automated entertainment...(notas nuestras) [xxxi]. A través de unos pocos ejemplos hemos constatado la forma en que los juguetes fonográficos contribuyeron a esta "mezcla semiótica" de signos, códigos y mensajes culturales. Podríamos arriesgarnos y acuñar el término "iconofonotexto", para designar este entramado experiencial, en el cual imagen, movimiento, sonido y texto abonan a la modificación de las concepciones y mentalidades; ya sea a través de un simple juguete mecánico centenario, o del bombardeo constante de mensajes virtuales al que todos estamos sujetos en la mal llamada "nueva" sociedad mediática

\section{Notas al final:}

[i] Walter Benjamin. The Work of Art in the Age of Mechanical Reproduction, en Illuminations: Essays and Reflections, Hannah Arendt (ed.), Schocken Books, New York, 2007, páginas 217-252. Sobre el impacto cultural del medio fotográfico véase también, entre otros, a Michel Frizot. El imaginario fotográfico. Ediciones Ve S.A., Consejo Nacional para la Cultura y las Artes / UNAM / Fundación Televisa, 2009, y Pierre Sorlin. EI siglo de la imagen analógica: Los hijos de Nadar. Editorial La Marca, Biblioteca de la mirada, Buenos Aires, 1997

[ii] Freund, Giséle. La fotografía como documento social. Editorial Gustavo Gili, S.A., Barcelona, 1976

[iii] Ya desde inicios y mediados del siglo XIX existían esfuerzos y desarrollos tecnológicos dirigidos a la reproducción de sonidos, pero estos se limitaban a procedimientos de aplicabilidad científica enfocados en el estudio de las ondas sonoras. Ejemplo de uno de estos instrumentos es el "fonoautógrafo" desarrollado por el francés Edouard-Léon Scott en 1857. No obstante, estos desarrollos eran muy limitados y distan mucho del impacto cultural e industrial que representó el "fonógrafo" de Edison. El fonógrafo original de Edison consistía en un mecanismo mecánico-acústico, el cual grababa o inscribía las ondas sonoras sobre un cilindro recubierto de una cera o compuesto especial, ello a través de una aguja adherida a un diafragma vibrante. En su etapa comercial inicial, la empresa Edison Phonograph Company manufacturaba y vendía, tanto el fonógrafo como los pequeños cilindros con grabaciones musicales, discursos y otros sonidos de interés general.

\section{[iv] William Howland Kenney. Recorded Music in American Life: The Phonograph and Popular Memory} 1890-1945. Oxford University Press, 1999

[v] Recuperado del internet: www.razzarsharp.com/Phonographs/bOtherBrands.

[vi] Para un estudio más amplio de los antecedentes y evolución del cinematógrafo véase Stephen Herbert. A History of Pre-Cinema. Vol I. Routledge, 2001.

[vii] El primer filme sonoro de largo metraje fue The Jazz Singer (1927), de la Warner Brothers. Este dio impulso a la popularidad de los "talkies", llevando a la desaparición de muchos artistas de la época del cine silente, los cuales no pudieron hacer una transición efectiva al nuevo medio (similar a lo que surgió en la transición de los programas dramáticos radiales al medio televisivo en los años 50).

[viii] Jacobs Smith. Phonograph Toys and Early Sound Cartoons: Towards a History of Visualized Phonography, en Animation, 2012: Núm. 7, páginas 151-174 
[ix] Idem., páginas 151-153. El "phonoreel" era un rollo de de dibujos en serie individuales que al girarse rápidamente creaba la ilusión visual de movimiento. El mismo se colocaba en un aparato sobre el fonógrafo y era accionado por el movimiento circular del plato, al mismo tiempo que se reproducía la música del disco. Smith establece que esta es la primera referencia a una reproducción conjunta de imagen y sonido.

\section{[x] Pamela B. Nelson. Toys as History: Ethnic Images and Cultural Change. An Exhibition at the Balch} Institute for Ethnic Studies. Ferris State University, April-October 1990. Recuperado de www.ferris.edu/jjmcrow/links/toys/homepage.htm, página 1

[xi] Ibid.

[xii] Edward Said. Orientalism. Vintage Press. (1978), 1994, página 3

[xiii] lbid., página 4

[xiv] Ibid., página 205

[xv] Naomi, Rosenblatt. Orientalism in American Popular Culture. Penn History Review. Vol. 16, Núm. 2, 2009, páginas 51-63

[xvi] Muy en especial se destacan la "Columbian Exposition" de Chicago (1893) y la "Lousiana Purchase Exposition”, de San Luis (1904-1905). Rosenblatt destaca como en estas ferias o exposiciones, los pabellones y exhibiciones dedicadas a los países asiáticos y africanos eran los que más atraían las masas de público, movidos por el morbo y la curiosidad ante los temas "exóticos" o "pintorescos". Pabellones como los de Filipinas, China, Japón, Arabia, Egypto y Siam, entre otros, causaron gran sensación y aportaron a reforzar las tendencias y gustos orientalistas en la sociedad de la época (Ibid., páginas 51 y 58).

[xvii] Desde sus etapas iniciales Hollywood capitalizó la atracción del público hacia los temas orientales, proceso que se reforzó mucho más tras el revuelo internacional que provocó el descubrimiento de la tumba y riquezas del faraón Tutankamón (1922), evento que desató una obsesión generalizada por todo lo estéticamente egipcio u oriental (proceso de estetización que influenció significativamemte en el surgimiento posterior del llamado estilo "art deco"). En esta línea orientalista podemos destacar filmes como "Intolerancia" (1916), “Cleopatra” (1917), “El Jeque” (1921), “Los 10 Mandamientos" (1923), "El ladrón de Bagdad” (1924), "El Rey y yo" (Ana y el Rey de Siam, 1956) y "Lawrence of Arabia” (1962), entre muchos otros. Según Rosenblatt, estos filmes tipifican todos los estereotipos orientalistas sobre el medio oriente, representando sus tierras y culturas como hermosas, misteriosas, sexualmente atrayentes, mientras a sus habitantes como bárbaros, salvajes y tiránicos (Rosenblatt, Orientalism in American Popular Culture..., Op. Cit., página 61). Es interesante confirmar que estas nociones orientalistas prevalecen en producciones hollywoodenses contemporáneas, tal y como se evidencia de forma muy patente en los discursos orientalistas de películas tan recientes como "300" (2006), del director Zack Snyder, en la cual se idealiza la superioridad de la "civilización" y la "democracia" griegas por sobre las "bestias" tiránicas y bárbaras de los persas y sus vasallos.

[xviii] Said, Orientalism..., Op. Cit., página 207

[xix] Rosenblatt. Orientalism in American Popular Culture..., Op. Cit., página 58

[xx] Existen dos (2) modelos de Siam Soo, el original con soportes plegables y otro con soportes rígidos.

[xxi] Un anuncio de la época incluso indica concretamente : "Siam Soo dances to these Oriental Records". Se destacan entre otros títulos Dardanella (Columbia A2831), Karavan (Columbia A2931), Sweet Siamese (A2712), The Hula Blues (Columbia A3306), La Veda (Columbia A2972) y Behind your Silken Veil (Columbia A2758), entre otros. VéaseUlises Beato (Koenigsberg, Alex; ed.). SIAM SOO: She puts the Oh-Oh in Grafonola. Antique Phonograph Monthly. Vol. IX, Núm. 1. Recuperado de página de internet http://www.t-h-a-i-l-and.org/talkingmachine/siamsoo.html 
[xxiii] Un último dato curioso que podría tener relación con el origen de Siam Soo y su fuerte estereotipo orientalizado, gira en torno a la persona del propio Morton E. Converse, fundador y dueño de la compañía manufacturera homónima, creadora de la muñeca. Descendiente de una familia acomodada de inmigrantes franceses, Converse hizo de su compañía una de las empresas fabricantes de juguetes más grandes del mundo, sin dudas la más grande de los EEUU hacia fines de siglo XIX. Reflejo y ejemplo del típico "tycoon" acaudalado de inicios de siglo XX, Converse fue un asiduo viajero y aficionado a los "Grand Tours". En nuestra investigación en los archivos electrónicos de la "Historic Homes and Institutions and Genealogical and Personal Memoirs of Worcester County, Mass" y de la "History of Worcester Society of Antiquity", encontramos varias tarjetas postales enviadas por Converse a sus familiares desde varias localidades del mediano y lejano oriente. Una de éstas postales muestra al matrimonio Converse montando camellos frente a la esfinge y las pirámides de Egipto. Otra postal - aunque es evidente que es una composición posada dentro de un estudio fotográfico muestra al matrimonio en típicos carruajes individuales, tirados por corredores aparentemente hindúes. No es de extrañar que esta afición y experiencias de Converse en estos destinos "exóticos" hayan aportado a su visión orientalista, la cual encontraría una natural expresión en uno de sus más exitosos juguetes.

[xxiv] John J. Nagle. A Brief History of the National Company, Inc. Recuperado de http://www.qsl.net/jms/bio_rem/bhnc.html

[xxv] Nelson. Toys as History: Ethnic Images ..., Op. Cit.

[xxvi] El término "coon" es una derivación abreviada de "raccoon" (mapache), en alusión a las facciones de dicho animal que aparenta tener una máscara sobre sus ojos. La implicación se relaciona al blanco disfrazándose con facciones de negro. Por supuesto, parte de la burla peyorativa consistía en exagerar ciertos rasgos considerados cómicos, tales como labios gruesos (exagerados con pintura blanca o roja), así como ojos saltones. Existen múltiples ejemplos de la figura del "coon" y del nombre "rastus" empleados en anuncios publicitarios, juguetes, espectáculos, obras literarias, canciones, e incluso en cortos fílmicos de las etapas iniciales del cine silente. Una de las más famosas y longevas estrategias publicitarias fue el uso de un hombre negro de nombre "Rastus" como personaje principal de venta del producto Cream of Wheat, entre 1893 hasta 1925.

[xxvii] War Hysteria and the Persecution of German-Americans. Recuperado de http://www.authentichistory.com/1914-1920/2-homefront/4-hysteria/

[xxviii] El "Tío Sam" (Uncle Sam en inglés, derivado de las siglas U.S.) es un personaje del folclor norteamericano que representa la personificación nacional de los EEUU y, específicamente, del gobierno estadounidense. El primer uso del nombre se remonta a la Guerra de 1812. Habitualmente se representa como un hombre mayor, de semblante serio, pelo blanco, barba y vestido con ropa que asemeja a la bandera de los Estados Unidos. Irónicamente, la primera representación gráfica del personaje (ca. 1870) se atribuye a Thomas Nast, caricaturista de origen alemán.

[xxix] Nelson. Toys as History: Ethnic Images ..., Op. Cit.

[xxx] Como bien indica Jacob Smith: "The blatant erotic appeal of shimmy dolls makes it clear that these 'toys' were not been bought and enjoyed only by children, and are best placed in the context of a succession of national dance crazes fueled in part by the phonograph industry". Smith. Phonograph Toys and Early Sound Cartoons..., Op. Cit., página 160

[xxxi] Ibid., página 156

\section{REFERENCIAS BIBLIOGRÁFICAS Y HEMEROGRÁFICAS}

BEATO, U. (KOENIGSBERG, A., ed.). SIAM SOO: She puts the Oh-Oh in Grafonola. 
Antique Phonograph Monthly. Vol. IX, Núm. 1. Recuperado de página de internet http://www.t-h-a-i-l-and.org/talkingmachine/siamsoo.html

FITZGERALD, J. R. The Strange Case of Siam Soo. The box held the clue. Recuperado de http://www.t-h-a-i-Ia-n-d.org/talkingmachine/siamsoo.html

HERBERT, S. (2001).A History of Pre-Cinema. Vol I. Routledge.

HILLIER, M. (1976). Automata and Mechanical Toys. Londres: Bloomsbury Books.

HOWLAND KENNEY, W (1999). Recorded Music in American Life: The Phonograph and Popular Memory 18901945. Oxford University Press.

MALAWSKI, S. "The Secret Life of Siam Soo: Her Identical Twin Revealed in never Before Seen Detail”. In the Groove, 16, Julio 2003, páginas 4-5.

NAGLE, J. J. A Brief History of the National Company, Inc. Recuperado de http://www.qsl.net/jms/bio_rem/bhnc.html

NELSON, P. B. Toys as History: Ethnic Images and Cultural Change. An Exhibition at the Balch Institute for Ethnic Studies. Ferris State University, April-October 1990. Recuperado de www.ferris.edu/jjmcrow/links/toys/homepage.htm

ROLFS, J. Y R. (2004). Phonograph Dolls and Toys. Los Angeles: Mulholland Press.

ROSEnBlATT, N. (2009). "Orientalism in American Popular Culture". Penn History Review. Vol. 16, Núm. 2, páginas 51-63.

SAID, E. (1979). Orientalism. Vintage Press.

SHEA, R. A. Doll Mark Clues: Numbers in Antique Doll Marks, Part E. Vol. 6, First Edition.

SMITH, J. (2012). "Phonograph Toys and Early Sound Cartoons: Towards a History of Visualized Phonography", en Animation, Núm. 7, páginas 151-174.

V. AA.: War Hysteria and the Persecution of German-Americans. Recuperado de http://www.authentichistory.com/1914-1920/2-homefront/4-hysteria

\section{BREVE SEMBLANZA DEL AUTOR:}

Jorge L. Crespo Armáiz es natural de Manatí, Puerto Rico. Culminó su doctorado en Filosofía en "Historia de Puerto Rico y el Caribe", en el Centro Ricardo Alegría de Estudios Avanzados de Puerto Rico y el Caribe. Su especialidad se centra en el análisis crítico de las imágenes visuales, en particular la fotografía, y en su doble acepción como documento histórico y artefacto cultural.

Ámbitos. Revista Internacional de Comunicación, n.29, año 2015, tercer trimestre (verano).

Recibido: 02/07/2015

Aprobado: 14/07/2015 